Portland State University

PDXScholar

Civil and Environmental Engineering Master's

Project Reports

Civil and Environmental Engineering

2017

\title{
Trace Metals in Stormwater: Alternative Best Management Practices
}

Jennifer Ibeth Mora

Portland State University

Follow this and additional works at: https://pdxscholar.library.pdx.edu/cengin_gradprojects

Part of the Water Resource Management Commons

Let us know how access to this document benefits you.

\section{Recommended Citation}

Mora, Jennifer Ibeth, "Trace Metals in Stormwater: Alternative Best Management Practices" (2017). Civil and Environmental Engineering Master's Project Reports. 36.

https://doi.org/10.15760/CEEMP.22

This Project is brought to you for free and open access. It has been accepted for inclusion in Civil and Environmental Engineering Master's Project Reports by an authorized administrator of PDXScholar. Please contact us if we can make this document more accessible: pdxscholar@pdx.edu. 
Trace Metals in Stormwater: Alternative Best Management Practices

\title{
BY
}

Jennifer Mora

A research project report submitted in partial fulfillment of the requirement for the degree of

\section{MASTER OF SCIENCE IN CIVIL AND ENVIRONMENTAL ENGINEERING}

\author{
Project Advisor: \\ Dr. Gwynn R. Johnson \\ Portland State University \\ (C)2017
}




\section{ACKNOWLEDGEMENTS}

First and foremost, I would like to acknowledge and thank my advisor, Dr. Gwynn R. Johnson, and Portland State University for the opportunity to work on this challenging and interesting problem. I am especially thankful to Dr. Gwynn Johnson for her patience, guidance, and immense knowledge. Without her support, it would not have been possible to complete this research. Several individuals were instrumental in the completion of this work. I would like to thank Emily Heleva-Ponaski, a member of the Stormwater Research Group, for her help and collaboration on sample and filter media analysis, in addition to her work on the rainwater recipe. I thank my fellow labmates, Julie D. Luisi and Emily Heleva-Ponaski, for the stimulating discussions, sleepless nights, and encouragement we shared. I also want to thank Bashar Al-Daomi for sharing his $\mathrm{pH}$ meter and equipment to facilitate analysis. Last but not the least, I would like to thank my partner, Brian M. Williams, my parents, Jaime A. Mora and M. Teresa Mora, my family and friends, for their unconditional love, support and patience throughout this process. 


\begin{abstract}
Heavy metals, such as copper $(\mathrm{Cu})$ and zinc $(\mathrm{Zn})$, are considered hazardous in natural waters due to their toxicity and non-biodegradability. The focus of this study is to use batch experiments to investigate the heavy metal $(\mathrm{Cu}$ and $\mathrm{Zn})$ removal efficiency of perlite and Earthlite ${ }^{\mathrm{TM}}$ to improve in-situ filtration systems for stormwater catchment basins. Stormwater samples from two field sites in Portland, OR, chosen to represent a high-use commercial site and high-traffic urban road, were characterized to inform experimental design and compare to values found in literature. The Linear, Freundlich, and Langmuir isotherm models were used to describe equilibrium data and determine partitioning coefficients for singlemetal batch studies. Both the Freundlich and Langmuir models fit most single metal batch systems, while $\mathrm{Cu}$-Perlite, Zn-Perlite, and Zn-Earthlite ${ }^{\mathrm{TM}}$, were best fit by the Langmuir model, $\mathrm{R}^{2}=0.9594 ; 0.9538$; 0.9811, respectively. Competitive adsorption behaviors for $\mathrm{Cu}$ and $\mathrm{Zn}$ were evaluated using a synthetic stormwater recipe where relative concentrations of $\mathrm{Cu}$ and $\mathrm{Zn}$ were maintained to be consistent with representative stormwater samples. Perlite showed a decrease in the sorption capacity of $\mathrm{Cu}$ and $\mathrm{Zn}$ in the presence of competing ions in solution. Earthlite ${ }^{\mathrm{TM}}$ showed no difference in the affinity for copper uptake between competitive and non-competitive batch experiments. Earthlite ${ }^{\mathrm{TM}}$ affinity for $\mathrm{Zn}$ decreased by two orders of magnitude in the competitive batch system. The results from this study will be applied to estimate filter lifetime for traditional and advanced stormwater filter systems. These results will inform experimental design in dynamic flow-through experiments using various filter media thereby improving filter design and implementation of stormwater best management practices.
\end{abstract}




\section{TABLE OF CONTENTS}

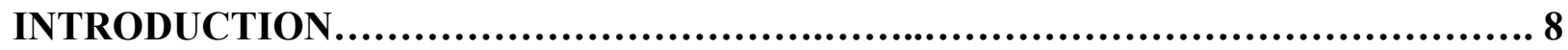

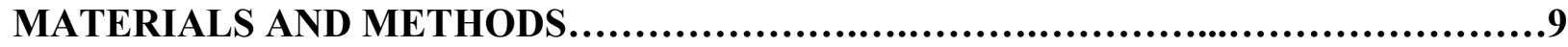

Stormwater Sample Collection ................................................9

Sample Characterization and Digest Procedures .................................9

Filter Media Characterization: Particle Size Analysis ..........................11

Synthetic Rainwater ..........................................................11

Analytical Procedures .......................................................12

Evaporative Concentrating .....................................................12

Standardization and QA/QC ...............................................12

Batch Procedures ............................................................14

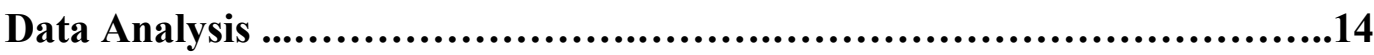

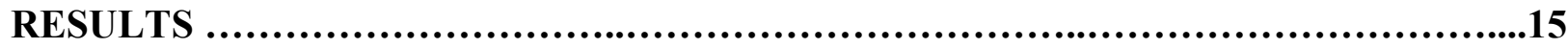

Stormwater Sample Characterization ........................................15

Particle Size Distribution......................................................17

Filter Media Efficiency and Modeling..........................................19

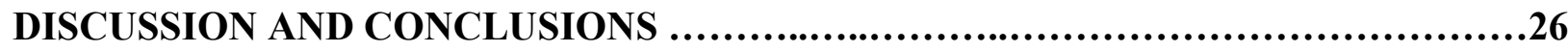

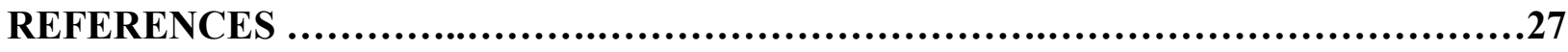

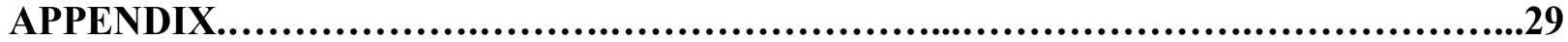




\section{List of Tables}

Table 1. Stock solution recipe of synthetic rainwater.

Table 2. Ion concentrations in synthetic rainwater compared to those reported in the literature.

Table 3. Concentrations of heavy metals, TSS, and $\mathrm{pH}$ as reported for Oregon and Portland.

Table 4. Measured TS, TSS, and TDS for stormwater collected in this study.

Table 5. Total recoverable metals for collected stormwater and synthetic stormwater.

Table 6. Average concentrations of trace metals in stormwater samples.

Table 7. Summary of mean sorption, equilibrium concentrations, and filter removal efficiency (\% concentration change) for Copper.

Table 8. Summary of mean sorption, equilibrium concentrations, and filter removal efficiency (\% concentration change) for Zinc.

Table 9. Sorption coefficients, isotherm constants, and $\mathrm{R}^{2}$ values for single-metal and competitive batch experiments in Perlite and Earthlite ${ }^{\mathrm{TM}}$ filter media.

\section{APPENDIX}

Table 10. Data for particle distribution analysis of Perlite and Earthlite

Table 11. Synthetic Stormwater Recipe for samples TA and TB tested for Total Recoverable Metals using EPA 200.8.

Table 12. ALS results for metal concentrations of stormwater from TriMet MERLO (A, B, C), PSU $4^{\text {th }}$ and Harrison and sludge from TriMet MERLO (A, B). 


\section{List of Figures}

Figure 1. Particle size distribution for Perlite and Earthlite ${ }^{\mathrm{TM}}$ with relative percentage of particles passing through based on particle size.

Figure 2. Single metal batch data for $\mathrm{Cu}$ in perlite with best fit Freundlich, Langmuir and/or Linear isotherm models.

Figure 3. Single metal batch data for $\mathrm{Zn}$ in perlite with best fit Freundlich, Langmuir and/or Linear isotherm models.

Figure 4. Single metal batch data for $\mathrm{Cu}$ in Earthlite ${ }^{\mathrm{TM}}$ with best fit Freundlich, Langmuir and/or Linear isotherm models.

Figure 5. Single metal batch data for $\mathrm{Zn}$ in Earthlite ${ }^{\mathrm{TM}}$ with best fit Freundlich, Langmuir and/or Linear isotherm models.

Figure 6. Experimental data means and standard error with best fit isotherm models for perlite with $\mathrm{Cu}$ and $\mathrm{Zn}$.

Figure 7. Experimental data means and standard error with best fit isotherm models for Earthlite ${ }^{\mathrm{TM}}$ with $\mathrm{Cu}$ and $\mathrm{Zn}$.

Figure 8. Perlite and Earthlite ${ }^{\mathrm{TM}}$ batch experimental data means and standard error with best fit isotherm models.

Figures 9. Competitive and Non-Competitive experimental data means and best fit isotherms for perlite with $\mathrm{Cu}$.

Figures 10. Competitive and Non-Competitive experimental data means and best fit isotherms for perlite with Zn.

Figures 11. Competitive and Non-Competitive experimental data means and best fit isotherms for Earthlite $^{\mathrm{TM}}$ with $\mathrm{Cu}$.

Figures 12. Competitive and Non-Competitive experimental data means and best fit isotherms for Earthlite $^{\mathrm{TM}}$ with Zn.

\section{APPENDIX}

Figure 13. Linearized Freundlich isotherm for single metal Cu-Perlite batch.

Figure 14. Linearized Freundlich isotherm for single metal Zn-Perlite batch.

Figure 15. Linearized Freundlich isotherm for single metal Cu-Earthlite ${ }^{\mathrm{TM}}$ batch.

Figure 16. Linearized Freundlich isotherm for single metal Zn-Earthlite ${ }^{\mathrm{TM}}$ batch.

Figure 17. Linearized Langmuir isotherm for single metal $\mathrm{Cu}-P e r l i t e ~ b a t c h$.

Figure 18. Linearized Langmuir isotherm for single metal Zn-Perlite batch.

Figure 19. Linear isotherm for single metal Cu-Earthlite ${ }^{\mathrm{TM}}$ batch.

Figure 20. Linearized Langmuir isotherm for single metal Zn- Earthlite ${ }^{\mathrm{TM}}$ batch. 
Figures 21. Competitive batch data for $\mathrm{Cu}$ in perlite with best fit Freundlich, Langmuir and/or Linear isotherm models.

Figures 22. Competitive batch data for $\mathrm{Zn}$ in perlite with best fit Freundlich, Langmuir and/or Linear isotherm models.

Figures 23. Competitive batch data for $\mathrm{Cu}$ in Earthlite ${ }^{\mathrm{TM}}$ with best fit Freundlich, Langmuir and/or Linear isotherm models.

Figures 24. Competitive batch data for $\mathrm{Zn}$ in Earthlite ${ }^{\mathrm{TM}}$ with best fit Freundlich, Langmuir and/or Linear isotherm models. 


\section{INTRODUCTION}

Removal of heavy metals from stormwater effluent is an important research topic due to the increase in contamination of natural waters. Heavy metals, such as copper $(\mathrm{Cu})$ and zinc $(\mathrm{Zn})$, are not degradable and can bioaccumulate, adversely affecting the health and viability of salmon, a measure of water quality in the Pacific Northwest (Baldwin et al., 2003; Nason et al., 2011; Arabyarmohammadi et al., 2016). Of the many sources that contribute to metal loadings, including roofing, building siding, atmospheric deposition and oil leaks, brake pad wear is the biggest source of $\mathrm{Cu}$ and $\mathrm{Zn}$ in stormwater effluent (Nason et al., 2012). An example of the state of Oregon's regulatory requirements for stormwater treated effluent limits for TSS, $\mathrm{Cu}$, and $\mathrm{Zn}$ are $100 \mathrm{mg} \mathrm{L}^{-1}, 22 \mu \mathrm{g} \mathrm{L}^{-1}$, and $140 \mu \mathrm{g} \mathrm{L}^{-1}$, respectively (EBS, personal communique). It may be of interest to note, a study by Baldwin et al. (2002) placed the toxicity threshold for juvenile Coho salmon to be $2.3-3.0 \mu \mathrm{g} \mathrm{L}^{-1}$, well below these treated effluent limits.

Of the different technologies used for removal of metals in solution, ion-exchange and adsorption mechanisms are proven to be highly effective and economical (Ghassabzadeh et al., 2010; Sari et al., 2007). Prefiltration systems, which consist of a customizable filter filled with filter media designed to target the pollutant of choice (Contech, 2017), are widely used in conjunction with pump and haul (e.g., the vacuum extraction, transport, and subsequent disposal of pollutants). The high costs associated with traditional pump and treat, in terms of disposal of removed solids, the energy cost, and large environmental footprint, motivate research on filter media to improve on-site filtration systems (EPA, 2009).

This study focuses on characterizing the performance of two filter media, perlite and Earthlite ${ }^{\mathrm{TM}}$. Perlite is a high porosity expanded volcanic rock that is economical and widely available (Ghassabzadeh et al., 2010) and is extensively used in stormwater catchment basins for removal of TSS, oil, and grease. Recent studies have shown perlite to have "fairly high" adsorption capacity for $\mathrm{Cu}$ (Ghassabzadeh et al., 2010) but few have examined heavy metal adsorption potential in a typical stormwater solution wherein the impact of competitive uptake may play a significant role in removal efficiencies. Deemed "an emerging and promising treatment technology," biochars are increasingly investigated for removal of heavy metals in aqueous solutions (Park et al., 2015; Komkiene et al., 2016; Chen et al., 2011) though there is limited information available on the competitive adsorption of metals on biochars. Furthermore, the sorption potential of biochar is difficult to qualify given the variability in composition and type of organic material used as source materials. Earthlite ${ }^{\mathrm{TM}}$, a proprietary biochar made with hazelnuts, expanded shale, compost and oyster shells, is touted as ideal for removal of heavy metals due to its high porosity, high specific surface area and cation exchange capacity (Earthlite $\left.{ }^{\mathrm{TM}}, 2017\right)$.

Overall, the aim of this study is to investigate the heavy metal removal efficiency of perlite and Earthlite $^{\mathrm{TM}}$ to improve in-situ filtration systems for stormwater catchment basins. The specific objectives are to: (1) characterize stormwater collected at various locations in Oregon to determine baseline concentrations for stormwater; (2) investigate the removal efficiency of perlite and Earthlite ${ }^{\mathrm{TM}}$ for copper and zinc; (3) determine the best-fit isotherm models to describe equilibrium data and estimate partitioning coefficients; and (4) evaluate the competitive adsorption behaviors of trace metals (copper and zinc) in perlite and Earthlite ${ }^{\mathrm{TM}}$. 


\section{MATERIALS AND METHODS}

\section{$\underline{\text { Stormwater Sample Collection }}$}

Stormwater samples were collected and analyzed in this study from two field sites, TriMet MERLO and downtown Portland (PSU $4^{\text {th }}$ Avenue and Harrison), each chosen for their high potential for heavy metal loadings based on their respective land use characteristics. Samples were collected from each site with the goal of characterizing stormwater effluent for "real world" environmental samples to inform future experimental design and compare to values found in literature.

TriMet MERLO, a garage facility and corporate headquarters for the greater Portland Metro bus service provider, was chosen to represent a high-use commercial site. Stormwater samples were collected from stormwater catchment basins at three locations on the TriMet MERLO site; specifically, the parking lot (A), bus route (B), and bus wash (C). Two of the locations, A and B (the parking lot and bus route, respectively), were of interest in terms of heavy metal concentrations considering the respective catchment basins had not been maintained for approximately 6 months, evidenced by the observed indicators of anoxic activity, strong odors of sulfur and methane. Sludge samples (as well as stormwater samples) were collected from these sites for testing and analysis. Grab samples of stormwater effluent were collected using 20 L polypropylene containers per Stormwater Methods and Procedures protocol 1060B. Specifically, the stormwater catchment basin was thoroughly mixed and a pre-rinsed bucket was used to collect a representative sample. The bucket sample was thoroughly mixed and funneled into a 20 L polypropylene container for transport and storage. Grab samples of sludge from sites A and B were collected and transported in plastic food-grade buckets for analysis in the lab.

The downtown Portland sampling location (PSU $4^{\text {th }}$ Avenue and Harrison) is a busy intersection in downtown Portland, adjacent to a highway offramp and heavy use bus stop, chosen to represent a high traffic urban road. Grab samples, used to represent a "snapshot" in both time and space" (Standard Methods, 1060B), were collected using a 500-ml polypropylene bottle and 20-L polypropylene container for long-term storage and transport. Polypropylene bottles were used to collect samples due to suspected preferential sorption of metals onto glass surfaces suggested in the literature.

Grab samples for each site were thoroughly mixed and separated into discreet acid-washed sample containers upon arrival in the laboratory. Trace metal grade nitric acid was used to acid fix samples to $\mathrm{pH}<2$ for long-term storage ( $<6$ months) and sample preservation per Standard Methods for the Examination of Water and Wastewater $1060 \mathrm{~A}$. The volume of acid necessary to achieve target $\mathrm{pH}<2$ was determined by testing a sample of comparable total volume. The determined volume of acid was added to relevant samples to acid fix at $\mathrm{pH}<2$ and recorded to account for dilution of original sample concentrations. Prior to acid fixing, the $\mathrm{pH}$ of environmental samples was measured using the Expandable IonAnalyzer EA920 at $25{ }^{\circ} \mathrm{C}$. Sample $\mathrm{pH}$ was recorded to inform future experimental design and compare to values found in literature.

\section{Sample Characterization and Digest Procedures}

Samples were tested (with the assistance of researchers in our stormwater research group) for total solids (TS), total dissolved solids (TDS), and total suspended solids (TSS) per Standard Methods for the Examination of Water and Stormwater 2540 B-D (the concentrations for total dissolved solids (TDS) were below reproducible levels using this method and subsequently estimated by mass balance). Particles greater than 0.25 inches were removed from samples prior to filtration to promote sample homogeneity. The filtering apparatus used for this study consisted of a 300-ml Kimble Kontes LLC Glass funnel with a glass base (47 mm), a 2000-ml graduated flask and Air Admiral Cole Palmer Vacuum (Model No. P79202-00 115V). 
Three discreet samples and a sample blank were tested for each of the four study sites. Total suspended solids (method $2540 \mathrm{D}$ ) were determined by filtering samples and measuring the solids remaining on the filter after drying in the oven at $105{ }^{\circ} \mathrm{C}$. The mass of individual Millipore filters (1.2$\mu \mathrm{m}$ particle retention) and aluminum weighing boats were recorded using a Mettler AJ100 analytical balance. Original sample containers were thoroughly shaken (approximately 10 seconds) to ensure discreet samples were homogeneous and representative. A small volume of nanopure water was used to pre-wet the filter prior to filtering the samples. Samples were poured into the filtering apparatus in a steady stream to ensure stability of the filter. Each filter was rinsed with three independent 10-ml aliquots of nanopure water in between samples and allowed to continue suction for 3 min after filtration to allow for removal of excess nanopure water. Filters were removed and placed in the pre-weighed aluminum weigh boats and dried at $105{ }^{\circ} \mathrm{C}$ in a VWR International 1350F convection oven for approximately one hour. After drying, samples were cooled and placed in a desiccator with White Drierite desiccant. Samples were dried, cooled, desiccated, and weighed until there was less than 4 percent difference between consecutive weights. Samples that did not meet this criterion were omitted from the results. Total suspended solids (TSS) were calculated using Equation 1 where $A$ is the weight of the filter plus dried residue (mg) and $B$ is the weight of the filter ( $\mathrm{mg}$ ).

$$
\operatorname{TSS}\left(\frac{m g}{L}\right)=\frac{(A-B) \times 1000}{\text { sample volume }(m l)}
$$

Total solids (method $2540 \mathrm{~B}$ ) were determined by evaporating a blank and three well-mixed homogeneous discreet volumes of sample from each site in a beaker using a VWR International 1350F convection oven. Samples were dried at approximately $98{ }^{\circ} \mathrm{C}$ to avoid cross-contamination or mass loss due to splattering. Samples were dried, cooled, desiccated, and weighed until there was less than 4 percent difference between consecutive weights. Samples that did not meet this criterion were omitted from the results. Total solids were calculated using Equation 2 where $A$ is the weight of the beaker plus dried residue ( $\mathrm{mg}$ ) and $B$ is the weight of the beaker $(\mathrm{mg})$.

$$
T S\left(\frac{m g}{L}\right)=\frac{(A-B) \times 1000}{\text { sample volume }(m l)}
$$

Total dissolved solids (method $2540 \mathrm{C}$ ) were determined by evaporating a composite sample of the filtrate from each study site in a VWR International $1350 \mathrm{~F}$ convection oven at $180{ }^{\circ} \mathrm{C}$. Each composite sample consisted of the filtrate, including rinse water used after filtration, of the discreet samples used in TSS analysis (described above) for each site. Samples were dried, cooled, desiccated, and weighed until there was less than 4 percent difference between consecutive weights. Samples that did not meet this criterion were omitted from the results. Total dissolved solids were calculated using Equation 3 where $A$ is the weight of the beaker plus dried residue $(\mathrm{mg})$ and $B$ is the weight of the beaker $(\mathrm{mg})$.

$$
\operatorname{TDS}\left(\frac{m g}{L}\right)=\frac{(A-B) \times 1000}{\text { sample volume }(m l)}
$$

Samples were tested for total recoverable elements, defined as "all metals inorganically bound, both dissolved and particulate," following Standard Methods 3030A, to fully characterize metal concentrations in stormwater samples. Three discreet samples from the PSU $4^{\text {th }}$ Avenue and Harrison site (4A, 4B, and 4C) were tested, along with two synthetic stormwater samples (synTA and synTB) created using sludge collected from the TriMet Merlo field site (sludges TA5 and TB5, respectively). Synthetic stormwater samples were created by blending a subsample of the respective sludge (TA5 from TriMet Merlo Parking Lot or TB5 from Trimet Merlo Bus Route) with a measured volume of synthetic rainwater (described below), targeting the measured total solids from the respective field site's stormwater samples (357 $\mathrm{mg} \mathrm{L}^{-1}$ and $128 \mathrm{mg} \mathrm{L}^{-1}$ for the parking lot and the bus route, respectively). 
Acid preserved sample aliquots $(200 \mathrm{ml})$ were transferred to a $250 \mathrm{ml}$ Griffin beaker where $4 \mathrm{ml}$ of (1:1) nitric acid:water and $2 \mathrm{ml}$ of $(1: 1) \mathrm{HCl}$ :water were added to each sample. The samples were evaporated on a hot plate set to approximately $85{ }^{\circ} \mathrm{C}$ until the sample volume was reduced to $20 \mathrm{ml}$ and then allowed to gently reflux for $30 \mathrm{~min}$. Upon cooling, the samples were quantitatively transferred to a $50 \mathrm{ml}$ volumetric flask, brought to volume using nanopure water, and analyzed for total recoverable metals using Shimadzu Atomic Absorption Spectrophotometer AA-7000. Samples that exceeded the linear range were diluted with nanopure water and reanalyzed.

\section{Filter Media Characterization: Particle Size Analysis}

A particle size analysis was completed with help from our stormwater research group for the filter media of interest per ASTM C136-01 Standard Test Method for Sieve Analysis of Fine and Coarse Aggregates and ASTM D2487-10 Standard Practice for Classification of Soils for Engineering Purposes (Unified Soil Classification System). ASHTO E-11 sieves 1/4", 4, 6, 10, 40 and 200 (6.3 mm, $4.75 \mathrm{~mm}$, $3.35 \mathrm{~mm}, 2.00 \mathrm{~mm}, 0.425 \mathrm{~mm}$ and $0.075 \mathrm{~mm}$, respectively) were used to define the particle size distribution. A $250-\mathrm{ml}$ beaker was used as the standard volume of measure to compare particle sizes between perlite and Earthlite ${ }^{\mathrm{TM}}$. The samples were shaken on a mechanical sieve shaker for 5 min to minimize formation of fine particles through degradation of perlite. The percentages passing, based on the total mass of the initial sample, were calculated to determine the sample particle size distribution.

\section{Synthetic Rainwater}

A synthetic rainwater solution recipe was derived by our stormwater research group from published studies by Jung and Werby (Jung, 1958; Jung et al., 1958) based on concentrations of inorganic ions in rainwater across the United States. The studies focused on ammonium, calcium, potassium, sodium, chloride, nitrate, and sulfate as ions of interest. Data for Portland, Oregon, was extrapolated from maps of ion concentration in rainwater. A stock solution of 1000x rainwater (see Table 1) was made using lab grade reagents and nanopure water. Nanopure water was mixed on a IKA-Vibrax-VXR orbital shaker at a speed sufficient to break the surface of the water and air-equilibrate for approximately 12 hours prior to use in the rainwater solution. 1X rainwater solutions were made by diluting the $1000 \mathrm{x}$ Rainwater stock using air-equilibrated nanopure water. A charge balance of the extrapolated concentrations resulted in concentrations for most ions, except for sodium and nitrate, to be within 10 percent error from reported concentrations for Portland, OR (Table 2). Concentrations for sodium and nitrate were adjusted from reported values to improve solubility of ions in solution. The rainwater recipe balanced at a $\mathrm{pH}$ of 5.6.

Table 1. Stock solution recipe of synthetic rainwater.

\begin{tabular}{|c|c|c|c|c|c|c|c|c|}
\hline \multicolumn{9}{|c|}{ 1000x Solution in 3 Liter } \\
\hline Available Chemicals & $\begin{array}{c}\text { Ammonium } \\
\text { Sulfate }\end{array}$ & $\begin{array}{c}\text { Sodium } \\
\text { Sulfate }\end{array}$ & $\begin{array}{c}\text { Potassium } \\
\text { Sulfate }\end{array}$ & Potassium Chloride & Calcium Nitrate & Sodium Nitrate & $\begin{array}{c}\text { Calcium Chloride } \\
\text { Dihydrate }\end{array}$ & $\mathrm{Ca}(\mathrm{OH}) 2$ \\
\hline Formula & (NH4)2SO4 & $\mathrm{Na} 2 \mathrm{SO} 4$ & $\mathrm{~K} 2 \mathrm{SO} 4$ & $\mathrm{KCl}$ & $\mathrm{Ca}(\mathrm{NO} 3) 24 \mathrm{H} 2 \mathrm{O}$ & $\mathrm{NaNO} 3$ & $\mathrm{CaCl} 22 \mathrm{H} 2 \mathrm{O}$ & $\mathrm{Ca}(\mathrm{OH}) 2$ \\
\hline FW (g) & 132.14 & 142 & 174.27 & 74.55 & 236.15 & 84.99 & 147.01 & 74.06 \\
\hline Equivalents & $2.00 \mathrm{E}+00$ & $2.00 \mathrm{E}+00$ & $2.00 \mathrm{E}+00$ & $2.00 \mathrm{E}+00$ & $2.00 \mathrm{E}+00$ & $2.00 \mathrm{E}+00$ & $2.00 \mathrm{E}+00$ & \\
\hline Equivalent weight (g) & $6.61 \mathrm{E}+01$ & $7.10 \mathrm{E}+01$ & $8.71 \mathrm{E}+01$ & $7.46 \mathrm{E}+01$ & $1.18 \mathrm{E}+02$ & $8.50 \mathrm{E}+01$ & $7.35 \mathrm{E}+01$ & $3.70 \mathrm{E}+01$ \\
\hline Solubility in $100 \mathrm{~g} \mathrm{H} 2 \mathrm{O}$ & $76.4 \mathrm{~g} / 100 \mathrm{~g}$ & & & $35.5 \mathrm{~g}$ & & & & \\
\hline mols in $1 \mathrm{gram}$ & 7.57E-03 & 7.04E-03 & $5.74 \mathrm{E}-03$ & 1.34E-02 & 4.23E-03 & $1.18 \mathrm{E}-02$ & $6.80 \mathrm{E}-03$ & 1.35E-02 \\
\hline$x$ grams & 0.6688 & 2.1091 & 0 & 0.3696 & 0 & 0.2495 & 2.0909 & 0 \\
\hline Normality & 0.0101 & 0.0297 & 0 & 0.005 & 0 & 0.0029 & 0.0284 & 0 \\
\hline mols in $\mathrm{x}$ gram & $5.06 \mathrm{E}-03$ & $1.49 \mathrm{E}-02$ & $0.00 \mathrm{E}+00$ & 4.96E-03 & $0.00 \mathrm{E}+00$ & 2.94E-03 & $1.42 \mathrm{E}-02$ & $0.00 \mathrm{E}+00$ \\
\hline
\end{tabular}


Table 2. Ion concentrations in synthetic rainwater compared to those reported in the literature.

\begin{tabular}{|c|c|c|c|c|c|c|c|}
\hline \multirow{2}{*}{ Cations } & \multirow{2}{*}{ Formula } & MW (g) & Junge Conc & Actual Concentration & Actual Concentration & Actual Concentration & \multirow{2}{*}{$\begin{array}{c}\% \text { Error from } \\
\text { Junge }\end{array}$} \\
\hline & & (g) & $\left(\mathrm{mg} \mathrm{L}^{-1}\right)$ & $\left(e q L^{-1}\right)$ & $\left(\mathrm{mg} \mathrm{L}^{-1}\right)$ & $\left(\mathrm{mmol} \mathrm{L}^{-1}\right)$ & \\
\hline Ammonium & $\mathrm{NH} 4+$ & 18 & 0.06 & $3.37 \mathrm{E}-06$ & 0.061 & 0.003374 & 1.2 \\
\hline Calcium & $\mathrm{Ca}++$ & 40.08 & 0.19 & $9.48 \mathrm{E}-06$ & 0.19 & 0.004741 & 0 \\
\hline Potassium & $\mathrm{K}+$ & 39.1 & 0.06 & $1.65 \mathrm{E}-06$ & 0.065 & 0.001653 & 7.7 \\
\hline Sodium & $\mathrm{Na}+$ & 22.99 & 0.48 & $1.09 \mathrm{E}-05$ & 0.25 & 0.01088 & 47.9 \\
\hline Hydrogen & $\mathrm{H}+$ & 1.0079 & & $6.31 \mathrm{E}-07$ & & & \\
\hline \multicolumn{8}{|l|}{ Anions } \\
\hline Chloride & $\mathrm{Cl}-$ & 35.45 & 0.41 & $1.11 \mathrm{E}-05$ & 0.395 & 0.011134 & 3.7 \\
\hline Nitrate & NO3- & 62 & 0.0975 & $9.79 \mathrm{E}-07$ & 0.061 & 0.000979 & 37.8 \\
\hline Sulfate & SO4-- & 96.06 & 0.67 & $1.33 \mathrm{E}-05$ & 0.638 & 0.006638 & 4.8 \\
\hline Hydroxide & $\mathrm{OH}-$ & & & $1.58 \mathrm{E}-08$ & & & \\
\hline
\end{tabular}

\section{$\underline{\text { Analytical Procedures }}$}

A Mettler AJ100 (range $0.0001-105 \mathrm{~g}$ ) was used for stock standard solutions and early experiments. A Mettler PJ3600 Delta Range analytical balance $(0.01-3000 \mathrm{~g})$ was used for masses that exceeded the Mettler AJ100 range. The Ohaus Adventurer AX 324 analytical balance (range $0.0001-$ $320 \mathrm{~g}$ ) was used for standards, sample dilutions, and mass in evaporative extractions. An Expandable ionAnalyzer EA920 (range 2.00 - 14.00 +/- 0.5) and Hanna Instrument HI 98190 pH/ORP meter (range $2.000-20.0000+/-0.1 \mathrm{pH}$ accuracy at 25 degrees $\mathrm{C}$ ) were used to measure $\mathrm{pH}$. The Shimadzu Atomic Absorption Spectrophotometer AA-7700 was used for analysis of trace metal concentrations in stormwater samples. The instrument was calibrated by conducting a line search/beam balance operation using the high standard concentration of the respective analyte range $\left(8 \mathrm{mg} \mathrm{L}^{-1}\right.$ for $\mathrm{Cu}$ and $2 \mathrm{mg} \mathrm{L}^{-1}$ for $\mathrm{Zn})$. Burner height was set to $7 \mathrm{~mm}$ per specifications in the Shimadzu Atomic Absorption Spectrophotometer AA-7000 Series Instruction Manual. Analysis was completed using a hollow cathode and deuterium lamp, for analysis of atomic absorption plus background and background, respectively. Rinse water blanks were adjusted ( $\mathrm{pH}$ and background ion concentrations) to match tested sample matrix. A Central Scientific CAT No $16674115 \mathrm{~V}$ hot plate was used for sample digests. An IKA-VIBRAXVXR orbital shaker was used to air-equilibrate nanopure water and thoroughly mix rainwater solutions. A Lab-line orbit shaker bath, Model 3540, was used for batch experiment procedures and a Barnstead NANOpure-Diamond ${ }^{\mathrm{TM}}$ system (Model No. D11901) was used to filter and purify nanopure water used in the experiments.

\section{Evaporative Concentrating}

Sample concentrations below AAS instrument detection limits were reduced in volume by evaporation in a VWR International $1350 \mathrm{~F}$ convection oven at $105{ }^{\circ} \mathrm{C}$. Sample bottles were weighed using Ohaus Adventurer AX324 analytical balance, in addition to pre- and post-evaporation masses, to calculate sample concentrations. Due to formation of precipitates upon evaporation, samples were acidified by addition of trace metal grade nitric acid to $\mathrm{pH}<2$. The volume of acid necessary to achieve target $\mathrm{pH}<2$ was determined by testing a sample of comparable total volume. The determined volume of acid was added to relevant samples to acid fix at $\mathrm{pH}<2$ and recorded to account for dilution of original sample concentrations. Acidified samples reflect free metal ion concentrations and are marked accordingly.

\section{Standardization and QA/QC}

Stock standard solutions (500 and $1000 \mathrm{mg} \mathrm{L}^{-1}$ ) were made using the relevant mass of $\mathrm{Cu}$ $\left(\mathrm{CuCl}_{2} * 2 \mathrm{H}_{2} \mathrm{O}\right)$ and $\mathrm{Zn}\left(\mathrm{ZnCl}_{2}\right)$ metal salts in a $2 \%$ nitric acid solution using trace metal grade acid and nanopure water. The linear range of the Shimadzu AAS instrument was established and tested regularly using a nine-point calibration procedure. The calibration standards were used to qualify the high, mid, 
and lower limits of the linear range for each target analyte. The linear range determined for $\mathrm{Cu}$ and $\mathrm{Zn}$ equaled $0.1-8 \mathrm{mg} \mathrm{L}^{-1}$ and $0.1-2 \mathrm{mg} \mathrm{L}^{-1}$, respectively.

A lab reagent blank (LRB), multiple lab fortified blanks (Cu/Zn, Cu-H, Cu-L, Zn-H, Zn-L), and a lab fortified matrix (4B*), a sample duplicate spiked with a known concentration using $500 \mathrm{mg} \mathrm{L}^{-1}$ stock solution, were processed with each batch of digest samples to test for quality control. The percent recovery was calculated for each analyte to determine the accuracy of the procedure using Equation 4 where $R$ is percent recovery, $L F B$ is the lab fortified blank, $L R B$ is the laboratory reagent blank and $s$ is the concentration equivalent of analyte added to fortify the LFB solution. The percent recovery of the analyte should fall within $85-115 \%$. Experimentally derived concentrations were compared to ALS lab tested samples for validation.

$$
R=\frac{L F B-L R B}{s} \times 100
$$

\section{Batch Procedures}

Batch experiments were used to qualify the adsorption of heavy metals, $\mathrm{Cu}$ and $\mathrm{Zn}$, onto perlite and Earthlite $^{\mathrm{TM}}$ filter media. The experimental design is consistent with the constant soil:solution method detailed in protocol EPA 530/SW-87/006 F (EPA Batch Type Procedures for Estimating Soil Adsorption of Chemicals).

Filter media were prepared for batch testing based on physical characteristics and measured particle size distributions. Perlite particles passing through ASHTO E-11 sieve \# 10 (2 mm) and retained on sieve \#40 (0.425 microns) were used throughout these experiments. A grab sample of Earthlite ${ }^{\mathrm{TM}}$ was collected from the source bag (Sunmark Environmental Services) after thoroughly mixing and used as received for particle size analysis and batch testing.

Six discrete aqueous-phase concentrations $\left(\mathrm{C}_{\mathrm{o}}\right)$ were used in "single metal" batch experiments (approximately $1,10,25,50,75$, and $100 \mathrm{mg} \mathrm{L}^{-1}$ ). These initial concentrations were created by diluting a $1000 \mathrm{mg} \mathrm{L}^{-1}$ stock using synthetic rainwater. Competitive sorption batch experiments (i.e., "multiple metal" batch experiments) were designed using a synthetic stormwater recipe reflecting relative concentrations of $\mathrm{Cu}$ and $\mathrm{Zn}$ as measured in the stormwaters collected for this study (TriMet MERLO and PSU $4^{\text {th }}$ Avenue and Harrison). The initial concentrations (approximately 10/25, 25/62.5, 50/125 $\mathrm{mg} \mathrm{L}^{-1}$ $\mathrm{Cu} / \mathrm{Zn}$, respectively) were diluted from $1000 \mathrm{mg} \mathrm{L}^{-1}$ stock synthetic rainwater. Each solution was adjusted to $\mathrm{pH} 6.2$ - 6.4 using trace metal grade $\mathrm{HNO}_{3}$ or $\mathrm{NaOH}$ reflecting the average $\mathrm{pH}$ of stormwater collected in this study. The volume added to adjust sample $\mathrm{pH}$ were recorded to account for dilution of original sample concentrations.

All batch experiments in this study were based on a 1:10 soil:solution ratio. Five discreet samples, in addition to a positive and negative control, were run for each $\mathrm{C}_{\mathrm{o}}$ concentration. Each acid-washed polypropylene bottle was weighed before addition of the filter media $(10 \mathrm{~g})$ and $\mathrm{pH}$-adjusted $\mathrm{C}_{\mathrm{o}}$ solution $(100 \mathrm{~g})$. The negative control, testing for background conditions or contaminated media, consisted of only synthetic rainwater and media. The positive control, testing for mass loss through adsorption to the bottles and overall stability of the target metal with the synthetic rainwater solution, consisted of filter media in a solution of synthetic rainwater and respective target metal.

Samples were set to mix at room temperature in an orbital shaker at approximately $75 \mathrm{rpm}$ for 24 hours to achieve chemical equilibrium. Per EPA 530/SW-86/006-F, "the equilibration time should be the minimum amount of time needed to establish a rate of change of the solute concentration in solution equal 
or less than 5\% per 24-hour interval" (EPA, 1992). The final mass of each bottle was recorded before and after the 24-hour equilibration time to account for mass loss in the system.

Following the 24 hour equilibration time, samples were allowed to settle gravimetrically for 1-2 hours, samples were filtered using Whatman 40 filters, and the eluent $\mathrm{pH}$ was recorded to account for changes in the sample matrix prior to analysis using Shimadzu Atomic Absorption Spectrophotometer AA-7000 (AA-Flame). Samples that exceeded the linear range of the AA-Flame were diluted with pHadjusted $(6.2-6.4)$ nanopure water and reanalyzed. The amount of solute adsorbed per mass of adsorbent $(\mathrm{S})$ was calculated by mass balance using Equation 5 .

$$
s=\frac{C_{o}-C_{E Q}}{m} *(V)
$$

where $S$ is the sorbed-phase concentration (mass of solute sorbed relative to mass of sorbent, $\mu \mathrm{g} \mathrm{g}^{-1}$ ), $C_{o}$ is the analytically determined initial solute concentration in solution $\left(\mathrm{mg} \mathrm{L}^{-1}\right), C_{E Q}$ is the final, aqueousphase equilibrium concentration of the solute $\left(\mathrm{mg} \mathrm{L}^{-1}\right)$, and $V$ equals the volume of solution $(\mathrm{mL})$. The resulting percent change in concentration measured after equilibrating for approximately 24 hours was calculated using Equation 6.

$$
\% \Delta C=\frac{C_{i}-C_{E Q}}{C_{i}} * 100
$$

where $\% \Delta C$ equals the percent change in solute concentration, $C_{i}$ is the analytically determined initial solute concentration in solution $\left(\mathrm{mg} \mathrm{L}^{-1}\right)$, and $C_{E Q}$ is as described previously.

\section{Data Analysis}

Adsorption isotherms were used to describe equilibrium data as a "graphic representation showing the amount of adsorbent as a function of the equilibrium concentrations of the solute" (EPA, 1992). This study compares measured results of batch sorption experiments using the Langmuir, the Freundlich, and the Linear isotherm models to describe equilibrium data and determine partitioning coefficients. The Langmuir (defined in Equation 8) and Freundlich (defined in Equation 9) models were linearized to facilitate analysis as shown below. The coefficient of determination $\left(\mathrm{R}^{2}\right)$ was calculated for each modeled equation to determine goodness of fit.

The traditional Langmuir sorption isotherm wherein there is an assumed maximum amount of available sorption sites on a given adsorbent is defined by Equation 8a.

$$
S=\frac{K_{L} M C_{E Q}}{\left(1+K_{L} C_{E Q}\right)}
$$

where $S$ represents the concentration of sorbate per mass of adsorbent ( $\left.\mathrm{mg} \mathrm{g}^{-1}\right), K_{L}$ is called the Langmuir constant and is often related to the capacity or affinity of the adsorbent $\left(\mathrm{L} \mathrm{mg}^{-1}\right), M$ represents the adsorption maximum of the adsorbent $\left(\mu \mathrm{g} \mathrm{g}^{-1}\right)$, and $C_{E Q}$ equals the measured equilibrium concentration of solute in solution $\left(\mathrm{mg} \mathrm{L}^{-1}\right)$. The traditional linearized Langmuir isotherm is shown in Equation $8 \mathrm{~b}$.

$$
\frac{C_{E Q}}{S}=\frac{1}{K_{L} M}+\frac{C_{E Q}}{M}
$$

where a plot of the relative concentration, $C_{E Q} / S$, versus $C_{E Q}$ will yield a straight line if the Langmuir isotherm models the measured sorption data with a slope equal to $1 / M$ and a y-intercept equal to $1 / K_{L} M$. 
The Freundlich sorption isotherm is an empirical relationship wherein it is assumed that the sorbent is composed of many different sorption sites (i.e., heterogeneous in nature) all having different sorption/binding energies. The model is defined by Equation 9a.

$$
S=K_{f} C_{E Q}^{n}
$$

where $S$ and $C_{E Q}$ are as defined above, $K_{f}$ is the Freundlich constant, related to the capacity or affinity of the adsorbent, and $n$ equals the Freundlich exponent, an indicator of the diversity of adsorption binding energies for the heterogeneous sorbent. The linearized Freundlich is shown in Equation 9b.

$$
\log (S)=\log K_{f}+n \log C_{E Q}
$$

where a log-log plot of the sorbed-phase concentration versus the measured equilibrium aqueous-phase concentration of solute will yield a straight line if the Freundlich model effectively describes the sorbent's uptake of solute with a slope equal to $n$ and a y-intercept equal to $\log K_{f}$.

\section{RESULTS}

\section{Stormwater Sample Characterization}

Table 3 shows concentrations of $\mathrm{pH}$, TSS, dissolved organic carbon (DOC), and trace metals as reported in the literature. Published values were based on the median range of heavy metal concentrations, DOC, and $\mathrm{pH}$ from samples collected at 22 sites throughout Oregon, 5 of which were in Portland (Nason et al., 2012). The higher median range for concentration of metals and dissolved organic carbon in Portland as compared to Oregon may be explained by Portland's higher population density relative to the other sites included in the study (e.g., Corvallis, Wemme, and Bend).

Table 3. Concentrations of heavy metals, TSS, and $\mathrm{pH}$ as reported for Oregon and Portland.

\begin{tabular}{|c|c|c|c|c|}
\hline \multicolumn{1}{|c|}{$\begin{array}{c}\text { Water } \\
\text { Quality }\end{array}$} & \multicolumn{2}{|c|}{ Davis et al., 2000 } & \multicolumn{2}{c|}{ Nason et al., 2012 } \\
\hline & $\left(\mathrm{mg} \mathrm{m}^{-2-} \mathrm{yr}\right)$ & $\left(\mathrm{mg} \mathrm{m}^{-2}\right.$-day) & Median range for 22 sites in OR*** & $\begin{array}{c}\text { Median range } \\
\text { for 5 sites in } \\
\text { Porltand, OR }\end{array}$ \\
\hline pH & -- & -- & $\left(\mathrm{mg} \mathrm{L}^{-1}\right)$ & $\left(\mathrm{mg} \mathrm{L}^{-1}\right)$ \\
\hline TSS & -- & -- & $6.76-6.92$ & $6.24-7.15$ \\
\hline DOC & -- & -- & $26.1-163$ & $23.1-118$ \\
\hline Copper & 24.3 & 0.0666 & $2.5-7$ & $5.88-9.97$ \\
\hline Zinc & 216 & 0.5918 & $0.00908-0.0409$ & $0.0368-0.0609$ \\
\hline Lead & 0.22 & 0.0006 & $0.0586-0.162$ & $0.106-0.219$ \\
\hline Cadmium & 18 & 0.0493 & $0.00686-0.018$ & $0.011-0.0313$ \\
\hline & & & BRL - 0.00068 & $0.037-0.074$ \\
\hline
\end{tabular}


The average concentrations of total solids (TS), total dissolved solids (TDS) and total suspended solids (TSS) measured from stormwater samples collected in this study at TriMet MERLO and in downtown Portland (PSU $4^{\text {th }}$ and Harrison) are reported in Table 4. TSS levels in all samples, except for the TriMet MERLO parking lot (A), were within range of expected TSS concentrations in Oregon as compared to published reports (Nason et al., 2012; Davis et al., 2000). Specifically, measured TSS values (30.0 - $\left.108 \mathrm{mg} \mathrm{L}^{-1}\right)$ for TriMet MERLO B, C and downtown Portland samples were consistent with published concentrations $\left(23.1-118 \mathrm{mg} \mathrm{L}^{-1}\right)$ for highway runoff in Portland. TSS for the TriMet parking lot (A) samples was considerably higher than highway runoff samples and consistent with expectations given the conditions of the catchment basin, not maintained for 6 months, and the specific land use characteristics of the site. The automobile density, brakes, tires, and oil residue from a parking lot are all sources of heavy metals and TSS that can contribute to elevated concentrations compared to highway stormwater runoff.

Table 4. Measured TS, TSS, and TDS for stormwater collected in this study.

\begin{tabular}{|c|c|c|c|c|}
\hline \multirow{2}{*}{ Site ID } & \multirow{2}{*}{ Sample ID } & TS & TSS & TDS \\
\cline { 3 - 5 } & & $\left(\mathrm{mg} \mathrm{L}^{-1}\right)$ & $\left(\mathrm{mg} \mathrm{L}^{-1}\right)$ & $\left(\mathrm{mg} \mathrm{L}^{-1}\right)$ \\
\hline \multirow{2}{*}{ Trimet MERLO } & B & $357 \pm 2.4$ & $326 \pm 11$ & BDL \\
\cline { 3 - 5 } & C & $128 \pm 1.2$ & $95.6 \pm 0.3$ & 58.0 \\
\hline \multirow{2}{*}{ PSU 4th \& Harrison } & Millipore & $90.6 \pm 8.8$ & $108 \pm 1.9$ & 80.6 \\
& Whatman & $138 \pm 5.8$ & $105 \pm 1.1$ & 66.3 \\
\hline
\end{tabular}

Summary results for the total recoverable metal concentrations, in $\mathrm{mg} \mathrm{L}^{-1}$, and percent recovery using EPA Digest 200.8 are shown in Table 3. Results from representative samples analyzed by ALS Environmental (a NELAP certified lab located in Kelso, WA) are also included for comparison in Table 5. Positive and negative controls were within the percent recovery limits $(85<\% \mathrm{R}<115)$ established by the EPA protocol. The only internal control to approach the percent recovery limit $(\% \mathrm{R}=115.58)$ was the lab fortified matrix, $4 \mathrm{~B}^{*}$. The quality of the digest procedure was not compromised considering sample $4 \mathrm{~B}^{*}$ is made up of the 4B sample matrix spiked with a known concentration of target metal, 5 and $2 \mathrm{mg} \mathrm{L}^{-1}$ of $\mathrm{Cu}$ and $\mathrm{Zn}$, respectively. As such, the percent difference reflects both the original sample concentration and the added concentration. A corrected percent difference for this value, accounting for the initial concentration, is $96.29 \%$ and $106.22 \%$ for $\mathrm{Cu}$ and $\mathrm{Zn}$, respectively. These values are within the percent recovery limits for this procedure.

The results of total metals measured for three discreet subsamples collected in downtown Portland (PSU $4^{\text {th }}$ and Harrison) were consistent in magnitude for both copper and zinc. Concentrations for this site ranged from approximately $20-30 \mu \mathrm{g} \mathrm{L}^{-1}$ for $\mathrm{Cu}$ and $120-200 \mu \mathrm{g} \mathrm{L}^{-1}$ for $\mathrm{Zn}$. The detected total metal concentrations are consistent with those expected highway runoff heavy metal concentrations as reported in the literature $\left(36.8-60.9 \mu \mathrm{g}-\mathrm{Cu} \mathrm{L}^{-1} ; 106-219 \mu \mathrm{g}-\mathrm{Zn} \mathrm{L}^{-1}\right)$ in Portland, OR (Nason et al., 
2012). A comparison of the experimental concentrations to independent ALS Environmental lab results was designed to further validate the digest procedure reported in this study and to facilitate a comparison of synthetic stormwater solutions created by mixing volumes of sludge (collected at TriMet MERLO sampling stations) with synthetic rainwater.

Measured trace metal concentrations for synthetic stormwater samples created by mixing a measured volume of sludge (either sludge TA or TB, collected at TriMet MERLO parking lot (A) or at the bus route (B)) shows some variability in the total metals in solution depending on the sludge source (either A or B, for example). These results are as expected considering the variable total metal concentrations detected in those discrete sludge samples collected at the field sites. For example, the average concentration of total copper equaled approximately 50 and $130 \mathrm{mg} \mathrm{kg}^{-1}$ for sludge A and B, respectively. Similarly, the average concentration of total zinc equaled approximately 220 and $1100 \mathrm{mg}$ $\mathrm{kg}^{-1}$ for sludge $\mathrm{A}$ and $\mathrm{B}$, respectively. Mean concentrations of total recoverable metals and standard error for the samples analyzed in this study compared to those analyzed by an independent, certified laboratory show reproducibility in the methods and confidence in the results (see Table 6). As described above, the mean concentrations for the synthetic stormwater samples are reflective of the variability inherent in making a stormwater solution from sludge samples.

\section{Particle Size Distribution}

The particle size analysis data for perlite and Earthlite ${ }^{\mathrm{TM}}$ is shown in Figure 1. The weighted average particle size (D50) for perlite equaled $4.1 \mathrm{~mm}$ compared to $3 \mathrm{~mm}$ for Earthlite ${ }^{\mathrm{TM}}$. The effective size (D10), particle diameter corresponding to 10 percent finer, for perlite and Earthlite ${ }^{\mathrm{TM}}$ equaled $2.4 \mathrm{~mm}$ and $0.9 \mathrm{~mm}$, respectively. The calculated uniformity coefficient value (D60/D10) for perlite, 2.3, is indicative of a poorly graded, uniform media where the particles are generally the same size. Conversely, Earthlite $^{\mathrm{TM}}$ has a calculated uniformity coefficient, 5, that qualifies it as well graded or indicative of particle sizes that are distributed over a wide range. This experiment served to inform experimental design for batch experiments. Due to the wide availability, potential variability in perlite by vendor, and the interest in using the batch results to inform future column studies, a specific particle range $(0.045$ microns $-2 \mathrm{~mm}$ ) was used for perlite batch experiments. Given the wide range of particle sizes in Earthlite $^{\mathrm{TM}}$, a representative sample was used to fully qualify sorption behavior of this media. 
Table 5. Total recoverable metals for collected stormwater and synthetic stormwater.

\begin{tabular}{|c|c|c|c|c|c|c|}
\hline & & Total Co & $r\left(\mu \mathrm{L} \mathrm{L}^{-1}\right.$ & Total Z & $\mathrm{nc}\left(\mu \mathrm{g} \mathrm{L}^{-1}\right)$ & \\
\hline Site ID & Sample ID & $C_{\text {(ALS) }}$ & $\mathrm{C}_{\text {(PSU) }}$ & $\mathbf{C}_{(\mathrm{ALS})}$ & $\mathrm{C}_{\text {(PSU) }}$ & \\
\hline & SynSW-TA1 & & 22.2 & & 93.8 & \\
\hline & SynSW-TA2 & 5.60 & & 17.8 & & \\
\hline & SynSW-TB1 & & 25.1 & & 206 & \\
\hline TriMet MERLO & SynSW-TB2 & 14.4 & & 110. & & \\
\hline & A1 & 16.3 & & 73.6 & & \\
\hline & $\mathrm{A} 2$ & 21.1 & & 96.1 & & \\
\hline & B1 & 13.8 & & 132 & & \\
\hline & B2 & 8.75 & & 89.7 & & \\
\hline & Subsample A & & 33.7 & & 200. & \\
\hline PSU 4th \& & Subsample B & & 31.1 & & 181 & \\
\hline Harrison & Subsample C & & 32.0 & & 181 & \\
\hline & Average & 20.4 & 32.3 & 123 & 187 & \\
\hline & Sample ID & Targe & $\left.\mathrm{ng} \mathrm{L}^{-1}\right)$ & Spiked & $\begin{array}{c}\text { Measured } \\
\mathrm{C}_{(\mathrm{PSU})}\end{array}$ & \%Recovery* \\
\hline & $4 \mathrm{~B}^{*}$ & $\mathrm{Cu}$ & 5 & 4.85 & 4.70 & 96.90 \\
\hline & & $\mathrm{Zn}$ & 2 & 1.93 & 2.23 & 115.00 \\
\hline & $C_{11} 7 n$ & $\mathrm{Cu}$ & 5 & 4.77 & 4.60 & 96.50 \\
\hline Controls & 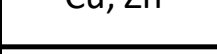 & $\mathrm{Zn}$ & 2 & 1.89 & 2.16 & 114.00 \\
\hline & $\mathrm{Cu}-\mathrm{H}$ & & & 4.97 & 4.68 & 94.20 \\
\hline & $\mathrm{Cu}-\mathrm{L}$ & & & 0.50 & 0.49 & 97.30 \\
\hline & $\mathrm{Zn}-\mathrm{H}$ & & & 1.92 & 2.11 & 110. \\
\hline & $\mathrm{Zn}-\mathrm{L}$ & & & 0.48 & 0.54 & 112.00 \\
\hline & Blank & $\mathrm{Cu}$ & $\mathrm{N} / \mathrm{A}$ & 0.00 & 0.01 & $\mathrm{~N} / \mathrm{A}$ \\
\hline & Diam & $\mathrm{Zn}$ & N/A & 0.00 & 0.03 & $\mathrm{~N} / \mathrm{A}$ \\
\hline
\end{tabular}

*Percent Recovery limits per EPA 200.8: $85<\% \mathrm{R}<115$ 
Table 6. Average concentrations of trace metals in stormwater samples.

\begin{tabular}{|c|c|c|}
\cline { 2 - 3 } \multicolumn{1}{c|}{} & \multicolumn{2}{c|}{$\mathrm{C}_{\text {MEAN }}(\mu \mathrm{g}$ g-1) } \\
\cline { 2 - 3 } \multicolumn{1}{c|}{} & $\mathrm{Cu}$ & $\mathrm{Zn}$ \\
\hline $\begin{array}{c}\text { PSU 4th \& } \\
\text { Harrison }\end{array}$ & $32.3+/-0.78$ & $187.40+/-6.52$ \\
\hline $\begin{array}{c}\text { PSU 4th \& } \\
\text { Harrison / ALS }\end{array}$ & $27.51+/-2.95$ & $161.64+/-16.2$ \\
\hline TA / ALS & $11.13+/-5.67$ & $43.12+/-25.78$ \\
\hline TB / ALS & $17.98+/-3.54$ & $142.09+/-32.27$ \\
\hline
\end{tabular}

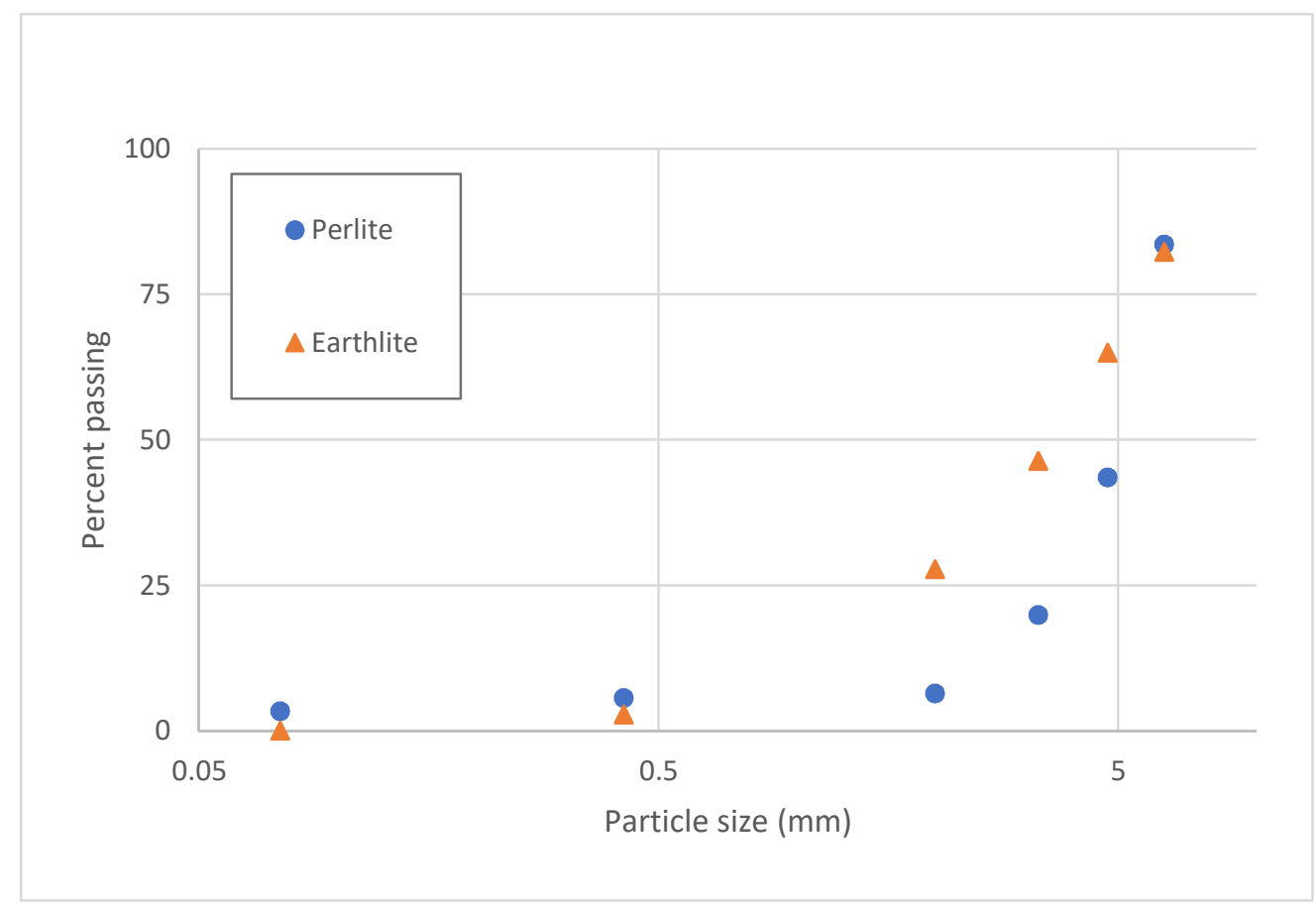

Figure 1. Particle size distribution for Perlite and Earthlite ${ }^{\mathrm{TM}}$ with relative percentage of particles passing through based on particle size.

\section{Filter Media Efficiency and Modeling}

Batch experiments served to inform the relationship between heavy metal concentrations and the removal efficiency of the various filter media. The mean equilibrium concentrations of copper measured in solution, sorption determined by mass balance, and the resulting percent change in concentration per measured initial aqueous-phase concentration of copper are presented in Table 7. Similar results for zinc are presented in Table 8. The batch data for the five discreet aqueous samples tested at each concentration show these results to be reproducible as indicated by the magnitudes of the standard square error reported accordingly (see Tables 7 and 8). The measured initial concentrations of the trace metals are based on measured concentrations in solution and reflect mass loss through formation of precipitates, 
for example, given that samples are filtered prior to analysis. As such, equilibrium concentrations for non-acidified samples reflect total dissolved metal ions.

Table 7. Summary of mean sorption, equilibrium concentrations, and filter removal efficiency (\% concentration change) for Copper.

\begin{tabular}{|c|c|c|c|c|c|c|c|c|}
\hline & \multicolumn{8}{|c|}{ Single Metal Batch Experiments } \\
\hline & \multicolumn{4}{|c|}{ COPPER-PERLITE } & \multicolumn{4}{|c|}{ COPPER-Earthlite $^{\mathrm{TM} * *}$} \\
\hline \multirow{2}{*}{ Sample ID } & \multicolumn{2}{|c|}{ 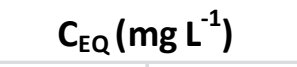 } & \multirow{2}{*}{$S\left(\mu g^{-1}\right)$} & \multirow{2}{*}{$\% \Delta$ Conc. } & \multicolumn{2}{|c|}{$\mathrm{C}_{\mathrm{EQ}}\left(\mathrm{mg} \mathrm{L}^{-1}\right)$} & \multirow{2}{*}{$\frac{\mathbf{S}}{\left(\mu \mathrm{g} \mathrm{g}^{-1}\right)}$} & \multirow{2}{*}{$\% \Delta$ Conc. } \\
\hline & mean & std error & & & mean & std error & & \\
\hline 1 & 0.085 & 0.0063 & 3.2 & 79 & 0.010 & 0.0034 & 4.0 & 97 \\
\hline 10 & 0.51 & 0.072 & 80 & 94 & 0.026 & 0.0021 & 62 & 99.6 \\
\hline 25 & 8.3 & 1.5 & 90 & 52 & 0.057 & 0.0025 & 240 & 99.8 \\
\hline 50 & 38 & 0.82 & 87 & 18 & 0.090 & 0.0044 & 490 & 99.8 \\
\hline 75 & 43 & 0.31 & 76 & 15 & 0.14 & 0.0038 & 710 & 99.8 \\
\hline \multirow[t]{3}{*}{100} & 67 & 0.43 & 88 & 12 & 0.16 & 0.0048 & 900 & 99.8 \\
\hline & \multicolumn{8}{|c|}{ Competitive (Multiple Metal) Batch Experiments } \\
\hline & \multicolumn{4}{|c|}{ COPPER-PERLITE } & \multicolumn{4}{|c|}{ COPPER-Earthlite ${ }^{\mathrm{TM}} * *$} \\
\hline Sample ID & \multicolumn{2}{|c|}{ 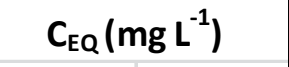 } & \multirow{2}{*}{$S\left(\mu g^{-1}\right)$} & \multirow[t]{2}{*}{$\% \Delta$ Conc. } & \multicolumn{2}{|c|}{ 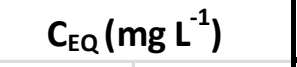 } & $S$ & $\% \Delta$ Conc. \\
\hline $\mathrm{Cu} / \mathrm{Zn}$ & mean & std error & & & mean & std error & $\left(\mu g^{-1}\right)$ & \\
\hline $10 / 25$ & 1.6 & 0.070 & 23 & 59 & 0.022 & 0.0020 & 57 & 99.6 \\
\hline $25 / 62.5$ & 17 & 0.50 & 53 & 24 & 0.047 & 0.0031 & 240 & 99.8 \\
\hline $50 / 125$ & 41 & 0.39 & 54 & 12 & 0.086 & 0.0068 & 440 & 99.8 \\
\hline & qui & n cor & ratio & $\mathrm{ied}$ & $m$ & nns. & & \\
\hline
\end{tabular}

Sorption magnitudes increased as concentrations increased until sorption reached a maximum capacity at higher concentrations where sorption magnitudes stabilized for all single-metal batch experiments (except for $\mathrm{Cu}-$ Earthlite $^{\mathrm{TM}}$ ). This trending behavior is consistent with the traditional Langmuir sorption isotherm wherein there is an assumed maximum amount of available sorption sites on a given adsorbent. The adsorption maximum of the adsorbent, $M$, derived by the Langmuir model for $\mathrm{Cu}$ Perlite, Zn-Perlite and Zn-Earthlite was $85.30,49.18$, and $1064.63 \mu \mathrm{g} \mathrm{g}^{-1}$, respectively. The difference in magnitudes of the adsorption maximum between $\mathrm{Cu}$ and $\mathrm{Zn}$ indicates perlite has a higher adsorption capacity for $\mathrm{Cu}$ as compared to $\mathrm{Zn}$ under these conditions. Sorption for the Copper-Earthlite ${ }^{\mathrm{TM}}$ batch was so effective that equilibrium concentrations exceeded the instrument lower detection limits and samples required evaporative concentrating for analytical detection. Due to formation of precipitates upon evaporation, samples were acidified and equilibrium concentrations and subsequent calculations reflect total metals in solution, which consist of total dissolved metals and total suspended metals (total dissolved metals reported in all other batch experimental results). The sorption values for these experiments are conservative considering non-acidified equilibrium concentrations would be lower, thus resulting in higher sorption values. 
Table 8. Summary of mean sorption, equilibrium concentrations, and filter removal efficiency (\% concentration change) for Zinc.

\begin{tabular}{|c|c|c|c|c|c|c|c|c|}
\hline & \multicolumn{8}{|c|}{ Single Metal Batch Experiments } \\
\hline & \multicolumn{4}{|c|}{ ZINC - PERLITE } & \multicolumn{4}{|c|}{ ZINC-Earthlite $^{\mathrm{TM} * *}$} \\
\hline \multirow{2}{*}{ Sample ID } & \multicolumn{2}{|c|}{$\mathrm{C}_{\mathrm{EQ}}\left(\mathrm{mg} \mathrm{L}^{-1}\right)$} & \multirow{2}{*}{$S\left(\mu g^{-1}\right)$} & \multirow{2}{*}{$\% \Delta$ Conc. } & \multicolumn{2}{|c|}{$\mathrm{C}_{\mathrm{EQ}}\left(\mathrm{mg} \mathrm{L}^{-1}\right)$} & \multirow{2}{*}{$S\left(\mu g g^{-1}\right)$} & \multirow{2}{*}{$\% \Delta$ Conc. } \\
\hline & mean & std error & & & mean & std error & & \\
\hline 1 & 0.030 & 0.0059 & 5.5 & 95 & 0.024 & 0.0016 & 7.5 & 96.9 \\
\hline 10 & 3.9 & 0.84 & 46 & 54 & 0.11 & 0.0045 & 104 & 99.0 \\
\hline 25 & 17 & 0.40 & 52 & 23 & 0.42 & 0.031 & 260 & 98.4 \\
\hline 50 & 38 & 0.31 & 50 & 12 & 1.3 & 0.10 & 490 & 97.4 \\
\hline 75 & 70 & 0.55 & 47 & 6.3 & 2.9 & 0.26 & 710 & 96.1 \\
\hline \multirow[t]{3}{*}{100} & 99.9 & 0.20 & 36 & 3.5 & 7.5 & 0.89 & 950 & 92.7 \\
\hline & \multicolumn{8}{|c|}{ Competitive (Multiple Metal) Batch Experiments } \\
\hline & \multicolumn{4}{|c|}{ ZINC-PERLITE } & \multicolumn{4}{|c|}{ ZINC-Earthlite $^{\mathrm{TM}} * *$} \\
\hline Sample ID & \multicolumn{2}{|c|}{$\mathrm{C}_{\mathrm{EQ}}\left(\mathrm{mg} \mathrm{L}^{-1}\right)$} & \multirow{2}{*}{$S\left(\mu g g^{-1}\right)$} & \multirow[t]{2}{*}{$\% \Delta$ Conc. } & \multicolumn{2}{|c|}{$\mathrm{C}_{\mathrm{EQ}}\left(\mathrm{mg} \mathrm{L}^{-1}\right)$} & \multirow{2}{*}{$S\left(\mu g g^{-1}\right)$} & \multirow[t]{2}{*}{$\% \Delta$ Conc. } \\
\hline $\mathrm{Cu} / \mathrm{Zn}$ & mean & std error & & & mean & std error & & \\
\hline $10 / 25$ & 21 & 0.22 & 21.2 & 9.17 & 21 & 0.22 & 23 & 10 \\
\hline $25 / 62.5$ & 60 & 0.46 & 30.5 & 4.80 & 60 & 0.46 & 22 & 3.5 \\
\hline $50 / 125$ & 119 & 1.3 & 33.5 & 2.72 & 119 & 1.3 & 76 & 6.0 \\
\hline & & Im $\mathrm{con}$ & tratio & $2 \mathrm{cod}$ & 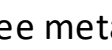 & ns. & & \\
\hline
\end{tabular}

To find the isotherm model that best fit the experimental data, comparisons of $\mathrm{R}^{2}$ values were carried out between the Linear, the Freundlich, and the Langmuir isotherm models (see Table 9). Both $\mathrm{Cu}$ and $\mathrm{Zn}$ in perlite, in addition to $\mathrm{Zn}$ in Earthlite ${ }^{\mathrm{TM}}$, fit both the Freundlich and Langmuir models well, but were fit best by a Langmuir model for single metal batch experiments as determined by the coefficient of determination $\left(\mathrm{R}^{2}=0.9594 ; 0.9538 ; 0.9811\right.$, respectively). The Cu-Earthlite ${ }^{\mathrm{TM}}$ system was best fit by the linear model, $\mathrm{R}^{2}=0.9893$. Measured sorption versus equilibrium concentrations (sorption isotherms) along with the best fit models are shown in Figures $2-7$. Both models fit data for the Zn-Earthlite ${ }^{\mathrm{TM}}$ system (Figure 7) well. The Freundlich model overestimates sorption at high concentrations for the ZnPerlite system as seen in Figure 3. The Langmuir model overestimates sorption at low concentrations for the $\mathrm{Cu}$ Earthlite ${ }^{\mathrm{TM}}$ batch (Figure 4). Both perlite and Earthlite ${ }^{\mathrm{TM}}$ have a higher sorption capacity for $\mathrm{Cu}$ as compared to $\mathrm{Zn}$, as can be seen in Figures 6 and 7. A plot of sorption versus equilibrium concentration with experimental data for all single metal batch experiments (Figure 8) further illustrates the difference in sorption behavior in perlite compared to Earthlite ${ }^{\mathrm{TM}}$, where maximum sorption values are less than 100 $\mu \mathrm{g} \mathrm{g}^{-1}$ in perlite and greater than $900 \mu \mathrm{g} \mathrm{g}^{-1}$ in Earthlite ${ }^{\mathrm{TM}}$. 
Table 9. Sorption coefficients, isotherm constants, and $\mathrm{R}^{2}$ values for single-metal and competitive batch experiments in Perlite and Earthlite ${ }^{\mathrm{TM}}$ filter media.

\begin{tabular}{|c|c|c|c|c|c|c|c|c|c|}
\hline \multirow{3}{*}{ Batch Exp. } & \multirow{3}{*}{ Batch ID } & \multicolumn{2}{|c|}{ Linear } & \multicolumn{3}{|c|}{ Freundlich } & \multicolumn{3}{|c|}{ Langmuir } \\
\hline & & $K_{d}$ & $\mathbf{R}^{2}$ & $K_{f}$ & $n$ & $\mathrm{R}^{2}$ & $K_{L}$ & $M$ & $\mathrm{R}^{2}$ \\
\hline & & $\left(\mathrm{L} \mathrm{kg}^{-1}\right)$ & & $\left(\mu \mathrm{g}^{(1-n)} \mathrm{m}^{(\mathrm{n})}\right) \mathrm{g}^{-1}$ & & & $\left(\mathrm{~L} \mathrm{mg}^{-1}\right)$ & $\left(\mu \mathrm{g} \mathrm{g}^{-1}\right)$ & \\
\hline \multirow{4}{*}{ Single-metal } & CU_P & 0.5333 & 0.8279 & 64.8819 & 0.0625 & 0.9270 & 0.6609 & 85.2954 & 0.9594 \\
\hline & ZN_P & 0.3071 & 0.8098 & 22.5949 & 0.3244 & 0.7839 & 2.4093 & 49.1777 & 0.9538 \\
\hline & CU_E** & 5880.3633 & 0.9893 & 12435.9536 & 1.4044 & 0.9748 & 0.6105 & 9584.0145 & 0.0382 \\
\hline & ZN_E & 55.7440 & 0.9814 & 385.9897 & 0.5208 & 0.9790 & 0.8155 & 1064.6291 & 0.9811 \\
\hline \multirow{4}{*}{ Competitive } & CU_P & 0.6934 & 0.9243 & 20.9192 & 0.2756 & 0.8031 & 0.5694 & 54.6825 & 0.9481 \\
\hline & ZN_P & 0.0996 & 0.7000 & 16.0894 & 0.1066 & 0.0230 & -2.3361 & 18.9969 & 0.5555 \\
\hline & CU_E** & 5255.1879 & 0.9604 & 13837.3055 & 1.3885 & 0.8793 & -5.5776 & -488.654 & 0.2909 \\
\hline & ZN_E & 0.5519 & 0.8169 & 3.1407 & 0.5795 & 0.3313 & 0.0028 & 190.5515 & 0.0098 \\
\hline
\end{tabular}

Plots of the experimental data with best fit models for the trace metals in competitive batch systems consist of 5 discreet samples at three relative concentrations of copper/zinc in solution (results not shown). These results allow for a comparison of relative magnitudes of sorption which may inform changes in the sorbing potential of each filter media due to competition. For example, in perlite, the maximum sorption value for copper in the presence of zinc is approximately half that measured for copper in single batch experiments (see Figure 9), an indication of the effects of competition. On the other hand, a comparison of the affinity of the sorbent, $K_{d}$, for $\mathrm{Cu}$ in Earthlite ${ }^{\mathrm{TM}}$ under competitive

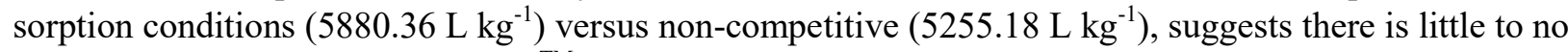
effect for copper uptake to Earthlite ${ }^{\mathrm{TM}}$ due to competition (see Figure 11) since magnitudes are consistent and within the same order of magnitude. 

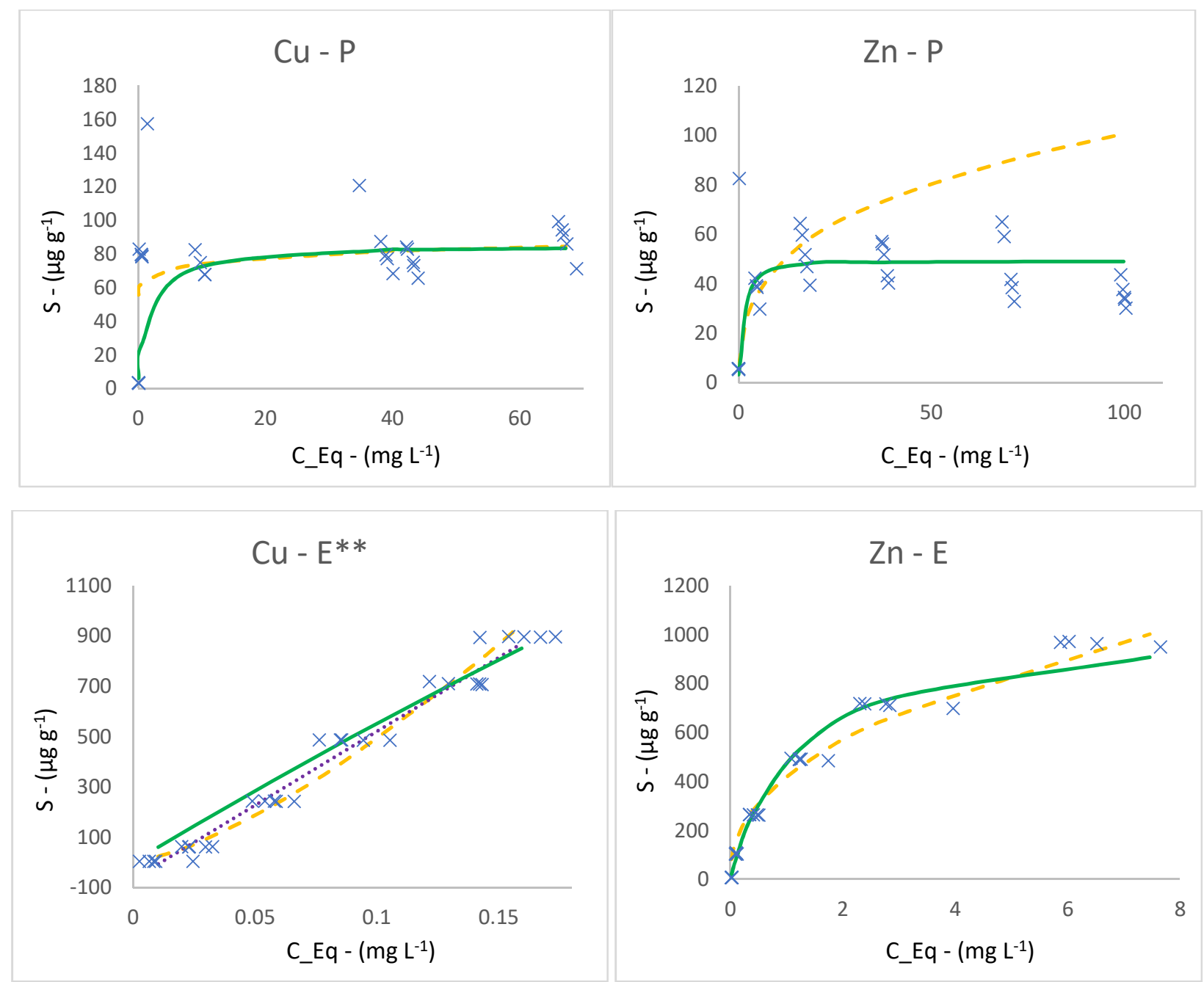

$\times$ Experimental Data $\quad$ - - - Freundlich _ Langmuir $\quad$ _......... Linear

Figures $2-5$. Single metal batch data for $\mathrm{Cu}$ and $\mathrm{Zn}$ in perlite and Earthlite ${ }^{\mathrm{TM}}$ with best fit Freundlich, Langmuir and/or Linear isotherm models. 

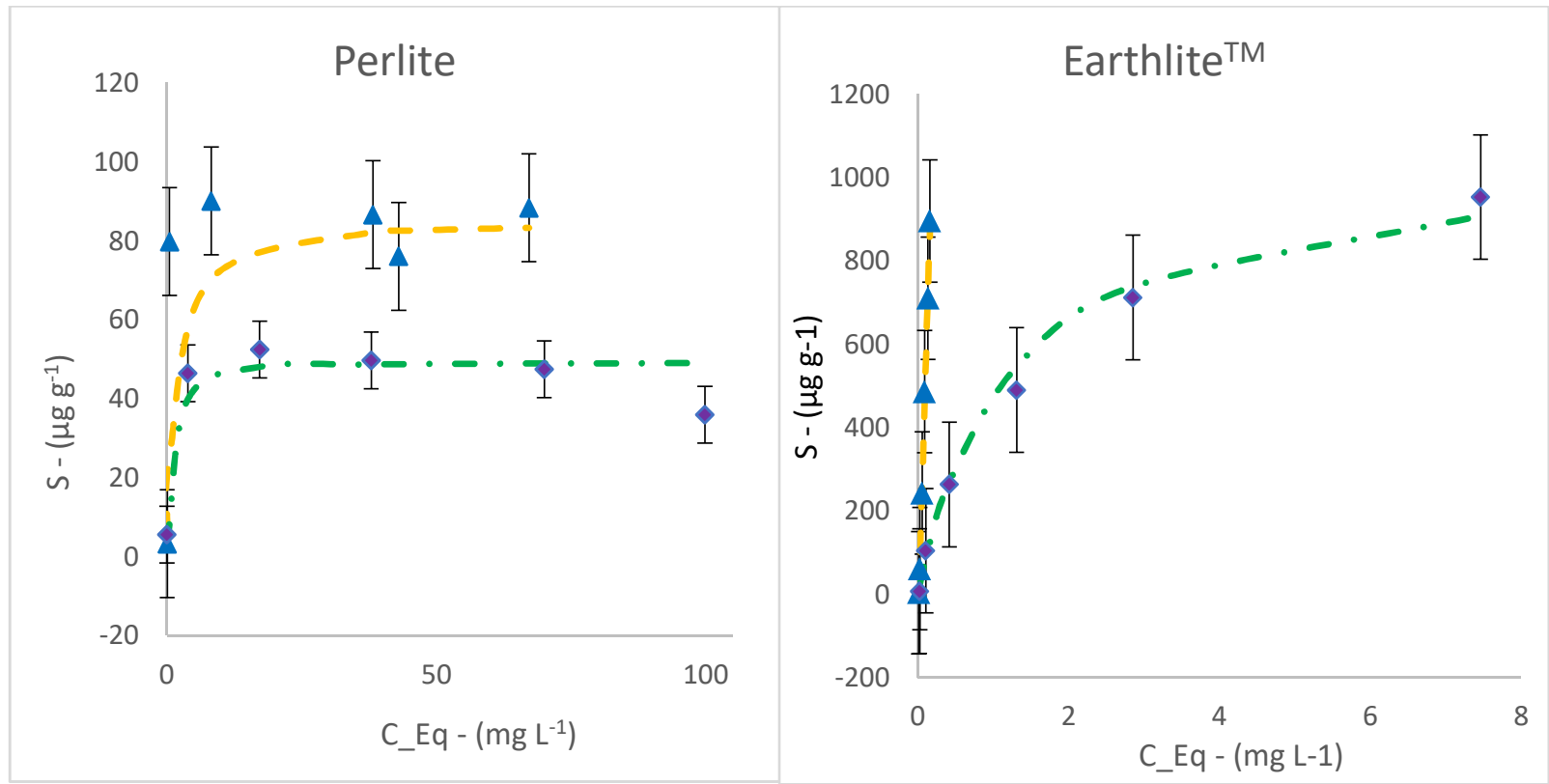

A Copper

- Copper - Best Fit

- Zinc

- - Zinc- Best Fit

Figures 6 and 7. Experimental data means and standard error with best fit isotherm models for perlite and Earthlite $^{\mathrm{TM}}$ with $\mathrm{Cu}$ and $\mathrm{Zn}$ (single metal batch experiments).

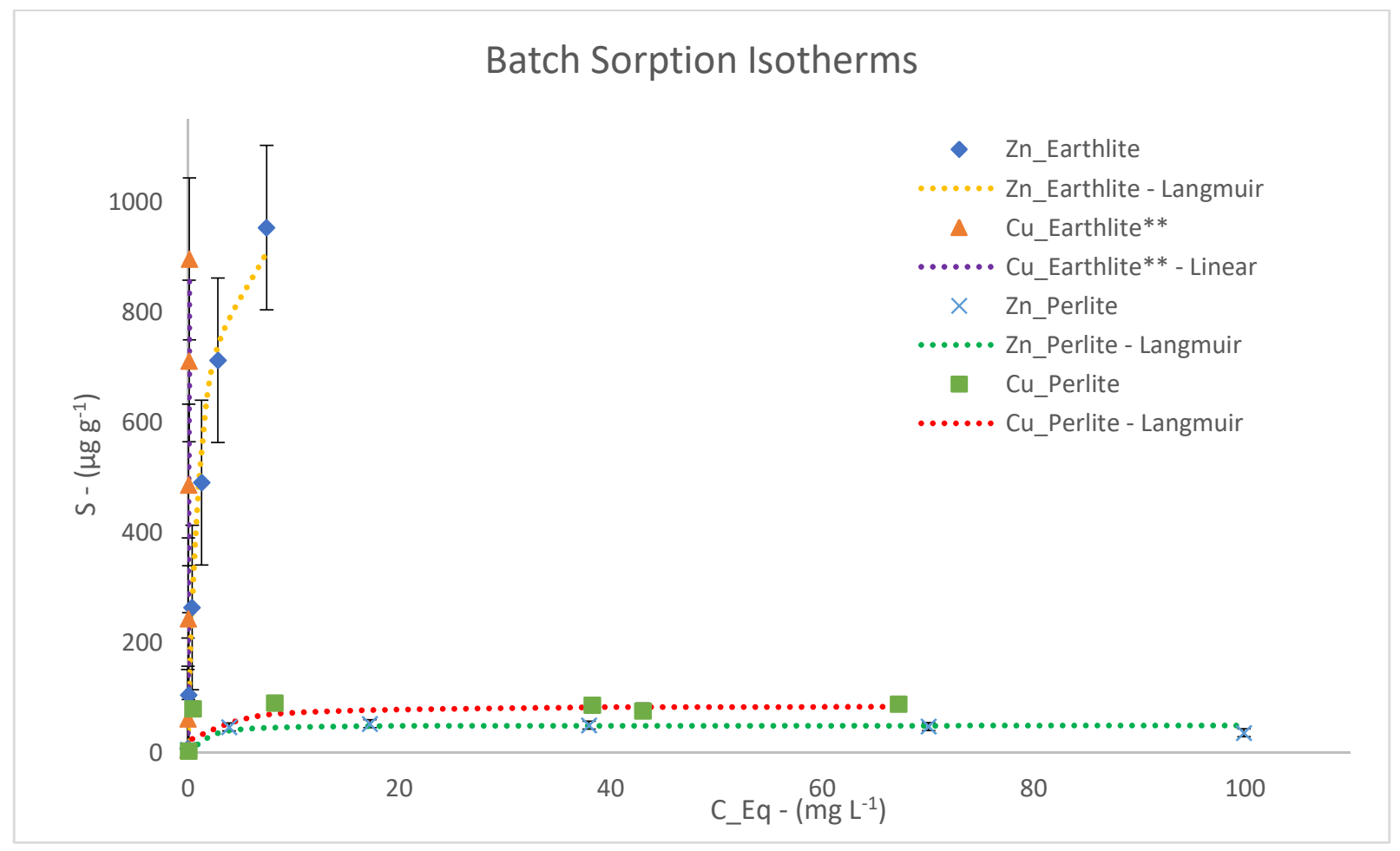

Figure 8. Perlite and Earthlite ${ }^{\mathrm{TM}}$ batch experimental data means and standard error with best fit isotherm models (single metal batch experiments). 

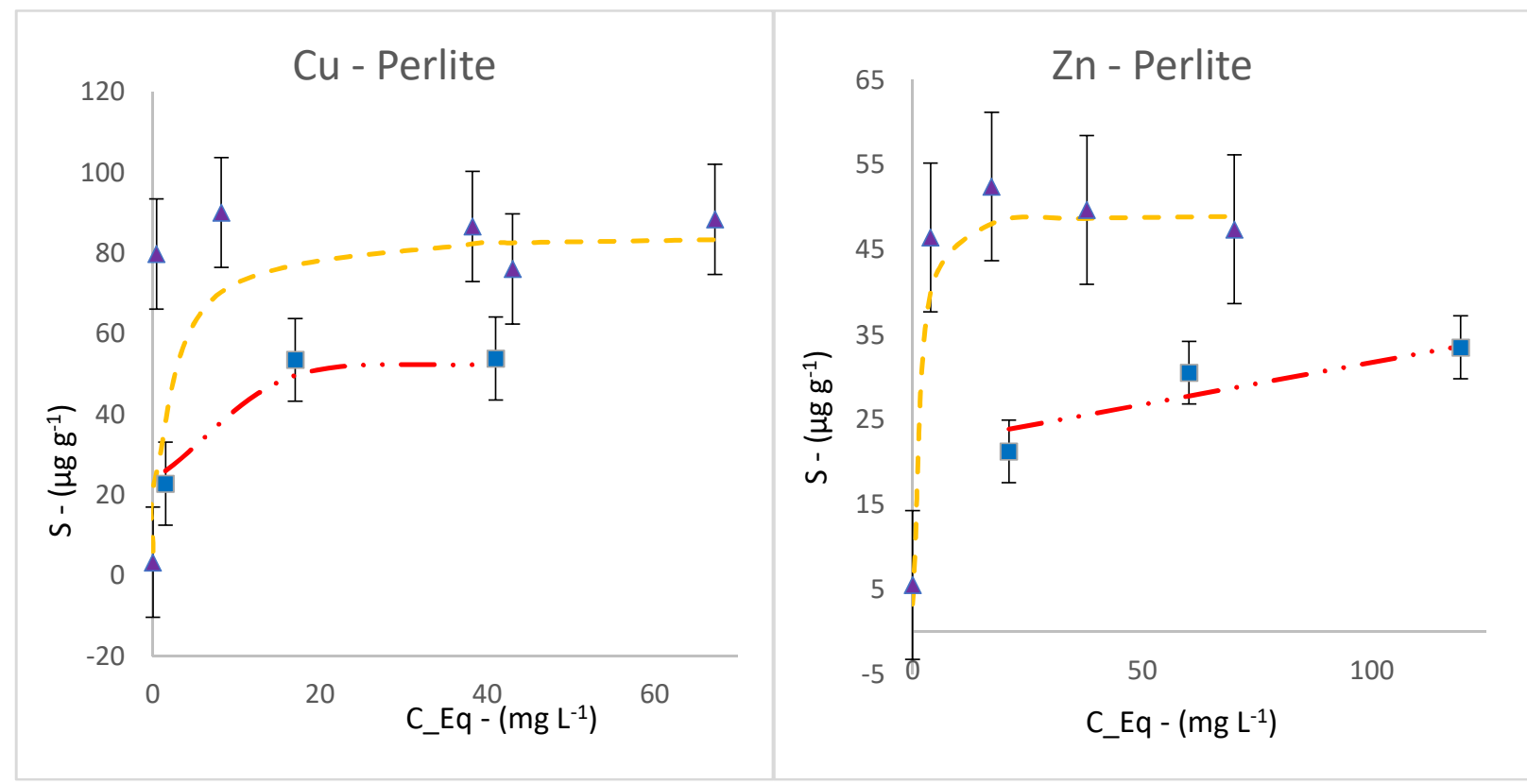

- Not Competitive

- - Not Competitive - Best Fit

- Competitive $\quad$ - . Competitive- Best Fit

Figures 9 and 10. Competitive and Non-Competitive experimental data means and best fit isotherms for perlite with $\mathrm{Cu}$ and $\mathrm{Zn}$.
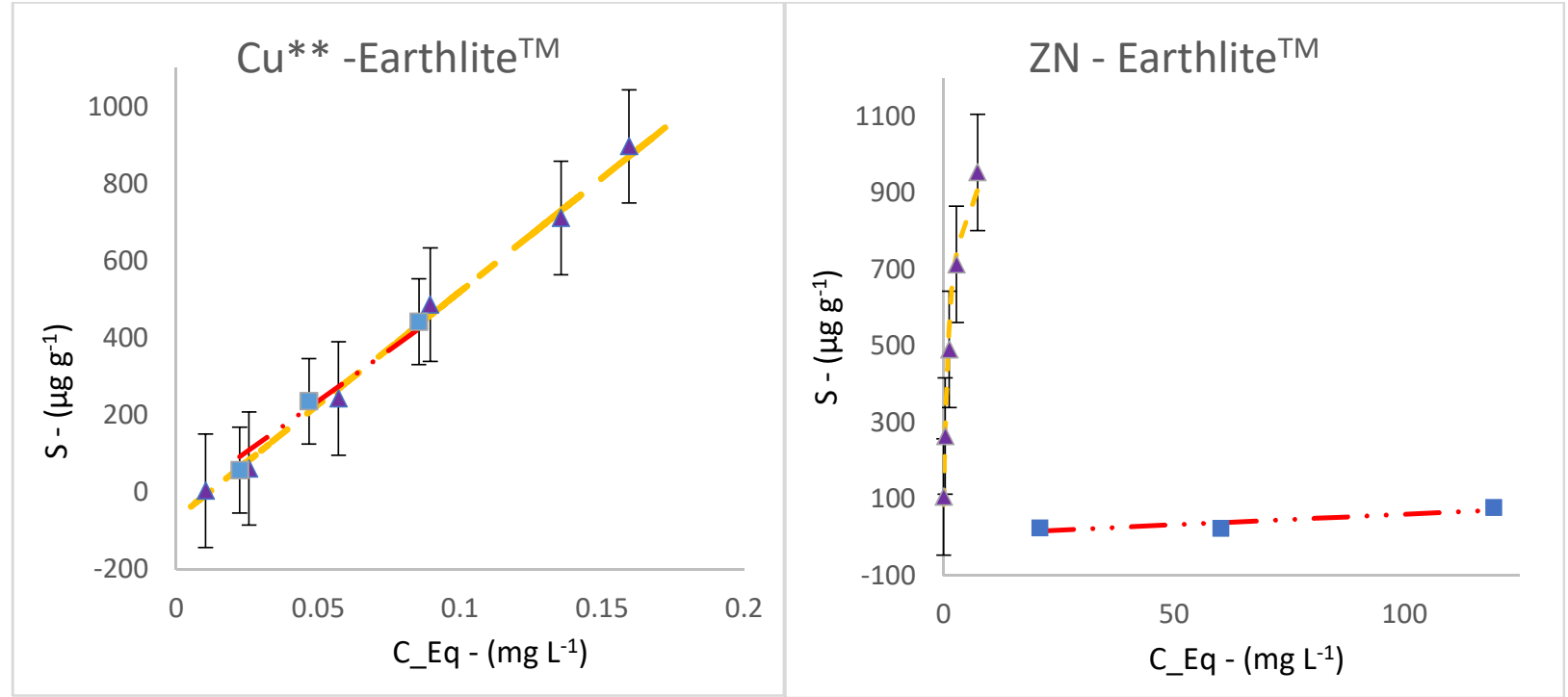

A Not Competitive $\quad-\quad-$ Not Competitive - Best Fit

- Competitive $\quad$ - . Competitive- Best Fit

Figures 11 and 12. Competitive and Non-Competitive experimental data means and best fit isotherms for Earthlite $^{\mathrm{TM}}$ with $\mathrm{Cu}$ and $\mathrm{Zn}$. 


\section{DISCUSSION AND CONCLUSIONS}

Tested sample concentrations agreed with published median range concentration values (Nason et al., 2012) of $\mathrm{Cu}, \mathrm{Zn}$, and TSS in Portland, OR. Tested concentrations ranged from $20-30 \mu \mathrm{g} \mathrm{L}^{-1}$ and $180-$ $200 \mu \mathrm{g} \mathrm{L}^{-1}$ for $\mathrm{Cu}$ and $\mathrm{Zn}$, respectively. To achieve regulatory limits for typical treated stormwater in Oregon, 26 percent removal of $\mathrm{Cu}$ and $22-30$ percent removal of $\mathrm{Zn}$ are required for established stormwater effluent concentrations. Data from batch experiments qualifies a 79 percent removal of $\mathrm{Cu}$ by perlite in the single metal batch at the target concentration, $1 \mathrm{mg} \mathrm{L}^{-1}$, and 59 percent in the competitive system at the target concentration, $10 \mathrm{mg} \mathrm{L}^{-1}$. Perlite removal of $\mathrm{Zn}, 95$ percent in the single metal batch for target concentration $1 \mathrm{mg} \mathrm{L}^{-1}$, was much lower (9 percent) in the competitive system, at $25 \mathrm{mg} \mathrm{L}^{-1}$.

Given the difference in tested, $25 \mathrm{mg} \mathrm{L}^{-1}$, and expected concentrations, $0.2 \mathrm{mg} \mathrm{L}^{-1}$, perlite removal of $\mathrm{Zn}$ is difficult to qualify in the competitive system in terms of those targeted effluent limits. However, it is expected that perlite removal of $\mathrm{Zn}$ will meet the necessary removal, 22 - 30 percent removal, to achieve established stormwater effluent concentrations. Earthlite ${ }^{\mathrm{TM}}$ removal of $\mathrm{Cu}$ was 99.8 percent in both the single metal and competitive batch experiments, whereas removal of $\mathrm{Zn}$ decreased from 97 percent in the single metal batch to less than 10 percent in the competitive batch. Competition from other metal ions in solution proved to be important to the sorption capacity for $\mathrm{Cu}$ and $\mathrm{Zn}$ in perlite, and $\mathrm{Zn}$ in Earthlite $^{\mathrm{TM}}$. Both perlite and Earthlite ${ }^{\mathrm{TM}}$ are expected to meet the necessary removal at established stormwater effluent concentrations per batch results for single metal and competitive batch experiments. Overall, batch results demonstrate Earthlite ${ }^{\mathrm{TM}}$ drastically outperformed perlite in terms of sorption capacity.

Much of the sorption behavior observed in this study can be modeled by the application of the Langmuir model, indicative of monolayer sorption and surface homogeneity of the adsorbent, that worked to describe sorption in the $\mathrm{Cu}$-perlite, $\mathrm{Zn}$-perlite and $\mathrm{Zn}$-Earthlite ${ }^{\mathrm{TM}}$ batch. Due to statistical reliability, the Langmuir model can be recommended to model sorption behavior of heavy metals in these systems. Behavior in the $\mathrm{Cu}$-Earthlite ${ }^{\mathrm{TM}}$ batch, a conservative estimate based on concentrations of free metal ions, was best fit by the Linear model, where affinity of the adsorbent was not dependent on concentration. This behavior was consistent for both single metal and competitive batch systems where sorption likely consists of complexation with surface functional groups on biochar, particularly carboxyl groups for example. Competitive experimental data revealed that both perlite and Earthlite ${ }^{\mathrm{TM}}$ preferentially sorbed $\mathrm{Cu}$ over $\mathrm{Zn}$. This could be explained by the difference in outer electron shells, where $\mathrm{Zn}$ has a full last sub orbital, $4 \mathrm{~s}^{2}$, as compared to $\mathrm{Cu}, 4 \mathrm{~s}^{1}$. For this reason, $\mathrm{Cu}$ is more effective at diffuse-layer and specific site binding as discussed by Breault et al. (1996).

The results from this experiment can be applied to estimate the filter lifetime for traditional and advanced stormwater filter systems. Sorption maximums measured and reported in this study can/will inform experimental design in dynamic flow-through experiments using perlite and Earthlite ${ }^{\mathrm{TM}}$ filter media. Additional research using complex stormwater matrices to qualify competition between other metals commonly found in stormwater effluent (e.g., aluminum and iron) would contribute to an improved assessment of filter design and implementation in stormwater best management practices. 


\section{REFERENCES}

Arabyarmohammadi, H., Mehdi Salaridirad, M., and Mohammadi, A., 2016. "Characterization and Utilization of Alunite Ore for Adsorptive Removal of Zinc: Batch and Column Study." Environmental Engineering and Management Journal, 15(12), 2761 - 2770.

APHA, 2005. Standard Methods for the Examination of Water and Waste Water, 21st ed. American Public Health Association, Washington, DC

Aydın, Bulut, and Yerlikaya, 2008. Removal of copper (II) from aqueous solution by adsorption onto low-cost adsorbents. Journal of Environmental Management, 87(1), 37-45.

Baldwin, D., Sandahl, J., Labenia, J., and Scholz, N., 2003. Sublethal effects of copper on Coho salmon: Impacts on nonoverlapping receptor pathways in the peripheral olfactory nervous system. Environmental Toxicology and Chemistry, 22(10), 2266-2274.

Breault, R. F., Colman, J. A., Aiken, G. R., and McKnight, D., 1996. Copper speciation and binding by organic matter in copper-contaminated streamwater. Environmental Science and Technology, 30(12), 3477-3486.

Chen, X., Chen, G., Chen, L., Chen, Y., Lehmann, J., Mcbride, Murray B., and Hay, A. G., 2011. Adsorption of copper and zinc by biochars produced from pyrolysis of hardwood and corn straw in aqueous solution. Bioresource Technology, 102(19), 8877-8884.

Contech Engineered Solutions, Web, visited June 1, 2017. $\mathrm{http}$ //www.conteches.com/products/stormwater-management/treatment/stormwater-managementstormfilter

Earthlite $^{\mathrm{TM}}$ Biochar Medias, Web, visited June 1, 2017. http://earth-lite.com/

EPA. 1992. "Batch-Type Procedures For Estimating Soil Adsorption of Chemicals," EPA/530/SW$87 / 006 \mathrm{a}$

EPA. 1994. "Method 200.8: Determination of Trace Elements in Waters and Wastes by Inductively Coupled Plasma-Mass Spectrometry," Revision 5.4.

EPA. 2009. "Green Remediation Best Management Practices: Pump and Treat Technologies," EPA 542F-09-005

Ghassabzadeh, Mohadespour, Torab-Mostaedi, Zaheri, Maragheh, and Taheri, 2010. Adsorption of Ag, $\mathrm{Cu}$ and $\mathrm{Hg}$ from aqueous solutions using expanded perlite. Journal of Hazardous Materials, 177(1), 950955.

Komkiene, J., and E. Baltrenaite, 2016. Biochar as Adsorbent for Removal of Heavy Metal Ions [Cadmium(II), Copper(II), Lead(II), Zinc(II)] from Aqueous Phase. International Journal of Environmental Science and Technology, 13(2), 471-482.

Junge., C and Werby, R.T., 1958. The Concentration of Chloride, Sodium, Potassium, Calcium and Sulfate in Rain Water Over the United States. Journal of Meteorology, 15(5), 417 - 425.

Jung., C., 1958. The Distribution of Ammonia and Nitrate in Rain Water over the United States. Transactions, American Geophysical Union, 39(2), 241 - 248. 
Nason, J., Nelson, P. O., Bloomquist, D. J., Sprick, M. S., 2011. Copper speciation in highway stormwater runoff as related to bioavailability and toxicity to ESA-listed salmon. Salem, OR : [Springfield, VA]: Oregon Dept. of Transportation, Research Section ; [Available through the National Technical Information Service].

Nason, J. A., Bloomquist, D. J., Sprick, M. S., 2012. Factors influencing dissolved copper concentrations in Oregon highway storm water runoff. Journal of Environmental Engineering, 138(7), 734-742.

Park, J., Cho, J., Ok, Y., Kim, S., Kang, S., Choi, I.,Seo, D., 2015. Competitive adsorption and selectivity sequence of heavy metals by chicken bone-derived biochar: Batch and column experiment. Journal of Environmental Science and Health, Part A, 50(11), 1194-1204.

Sar1, Tuzen, Citak, and Soylak, 2007. Adsorption characteristics of $\mathrm{Cu}(\mathrm{II})$ and $\mathrm{Pb}$ (II) onto expanded perlite from aqueous solution. Journal of Hazardous Materials, 148(1), 387-394. 


\section{APPENDIX}

Table 10. Data for particle distribution analysis of Perlite and Earthlite

\begin{tabular}{|c|c|c|c|c|c|c|}
\hline Media & Perlite & & & & & \\
\hline Test Duration & 5 minutes & & & & & \\
\hline Sieve Number & $\begin{array}{c}\text { Mass Total (pan+media) } \\
\text { (g) }\end{array}$ & $\begin{array}{l}\text { Mass media } \\
\text { (g) }\end{array}$ & $\%$ on Sieve & Cumulative \% & $\begin{array}{c}\text { Particle Size } \\
(\mathrm{mm})\end{array}$ & Percent Passing \\
\hline $1 / 4$ & 347.93 & 10.95 & 16.4 & 16.43 & 6.3 & 83.57 \\
\hline 4 & 374.62 & 26.69 & 40.1 & 56.48 & 4.75 & 43.52 \\
\hline 6 & 390.36 & 15.74 & 23.6 & 80.1 & 3.35 & 19.9 \\
\hline 10 & 399.34 & 8.98 & 13.5 & 93.58 & 2 & 6.42 \\
\hline 40 & 399.88 & 0.54 & 0.8 & 94.39 & 0.42 & 5.61 \\
\hline 200 & 401.36 & 1.48 & 2.2 & 96.61 & 0.075 & 3.39 \\
\hline \multirow[t]{2}{*}{$>200$} & 403.62 & 2.26 & 3.4 & 100 & $<0.075$ & 0 \\
\hline & Total Mass & 66.64 & & & & \\
\hline Weighted Average Particle Size & & 4.1 & $\mathrm{~mm}$ & & & \\
\hline \multirow[t]{3}{*}{ Ideal Column Diameter } & & 207 & $\mathrm{~mm}$ & & & \\
\hline & & 18 & $\mathrm{~cm}$ & & & \\
\hline & & 7.1 & inch & & & \\
\hline d60 (size at $60 \%$ finer) & & 5.4 & $\mathrm{~mm}$ & & & \\
\hline d10 (size at $10 \%$ finer) & & 2.4 & $\mathrm{~mm}$ & & & \\
\hline$u=d 60 / d 10$ & & 2.3 & & & & \\
\hline Media & Earthlite & & & & & \\
\hline Test Duration & 8 minutes & & & & & \\
\hline \multirow{2}{*}{ Sieve Number } & Mass Total (pan+media) & Mass media & \multirow{2}{*}{$\%$ on Sieve } & \multirow{2}{*}{ Cumulative \% } & Particle Size & \multirow{2}{*}{ Percent Passing } \\
\hline & $(g)$ & (g) & & & $(\mathrm{mm})$ & \\
\hline $1 / 4$ & 375.26 & 38.28 & 17.7 & 17.72 & 6.3 & 82.28 \\
\hline 4.00 & 412.67 & 37.41 & 17.3 & 35.05 & 4.75 & 64.95 \\
\hline 6.00 & 452.71 & 40.04 & 18.5 & 53.59 & 3.35 & 46.41 \\
\hline 10.00 & 493.02 & 40.31 & 18.7 & 72.25 & 2 & 27.75 \\
\hline 40.00 & 546.97 & 53.95 & 25 & 97.23 & 0.42 & 2.77 \\
\hline 200.00 & 552.95 & 5.98 & 2.8 & 100 & 0.075 & 0 \\
\hline \multirow[t]{2}{*}{$>200$} & 552.95 & 0 & 0 & 100 & $<0.075$ & 0 \\
\hline & Total Mass & 215.97 & & & & \\
\hline Weighted Average Particle Size & & 3 & $\mathrm{~mm}$ & & & \\
\hline \multirow[t]{3}{*}{ Ideal Column Diameter } & & 152 & $\mathrm{~mm}$ & & & \\
\hline & & 18 & $\mathrm{~cm}$ & & & \\
\hline & & 7.1 & inch & & & \\
\hline d60 (size at $60 \%$ finer) & & 4.4 & $\mathrm{~mm}$ & & & \\
\hline d10 (size at $10 \%$ finer) & & 0.9 & $\mathrm{~mm}$ & & & \\
\hline $\mathrm{u}=\mathrm{d} 60 / \mathrm{d} 10$ & & 5 & & & & \\
\hline
\end{tabular}

Table 11. Synthetic Stormwater Recipe for samples TA and TB tested for Total Recoverable Metals using EPA 200.8.

\begin{tabular}{|c|c|c|c|}
\hline $\begin{array}{c}\text { Sample } \\
\text { ID }\end{array}$ & TS & \% Solids & Sludge L-1 \\
\cline { 2 - 4 } & $\left(\mathrm{mg} \mathrm{L}^{-1}\right)$ & (solids sludge $\left.^{-1}\right)$ & $(\mathrm{mg})$ \\
\hline A & 357 & 36 & 996.4 \\
\hline B & 128 & 20 & 647.2 \\
\hline
\end{tabular}


Table 12. ALS results for metal concentrations of stormwater from TriMet MERLO (A, B, C), PSU $4^{\text {th }}$ and Harrison and sludge from TriMet MERLO (A, B).

\begin{tabular}{|c|c|c|c|}
\hline Sample ID & units & $\mathrm{Cu}$ & Zn \\
\hline TPL-A5-5 & $\left(\mathrm{g} \mathrm{g} \mathrm{g}^{-1}\right)$ & 21.1 & 96.1 \\
\hline TBR-B5-5 & $\left(\mu \mathrm{g} \mathrm{g}^{-1}\right)$ & 8.75 & 89.7 \\
\hline PSU-RW-4K & $\left(\mu \mathrm{g} \mathrm{g}^{-1}\right)$ & 20.6 & 126 \\
\hline PSU-RW-4L & $\left(\mathrm{g} \mathrm{g}^{-1}\right)$ & 20.1 & 120 \\
\hline SLG A1-2 & $\left(\mathrm{mg} \mathrm{Kg}^{-1}\right)$ & 51 & 209 \\
\hline SLG-A2-2 & $\left(\mathrm{mg} \mathrm{Kg}^{-1}\right)$ & 55.4 & 234 \\
\hline SLG-B1-2 & $\left(\mathrm{mg} \mathrm{Kg}^{-1}\right)$ & 136 & 1170 \\
\hline SLG-B2-2 & $\left(\mathrm{m} \mathrm{Kg}^{-1}\right)$ & 130 & 1100 \\
\hline ASYN 1-2 & $\left(\mathrm{g} \mathrm{g} \mathrm{g}^{-1}\right)$ & 3.44 & 9.4 \\
\hline ASYN 2-2 & $\left(\mathrm{gg} \mathrm{g}^{-1}\right)$ & 7.75 & 26.2 \\
\hline BSYN 1-2 & $\left(\mathrm{gg} \mathrm{g}^{-1}\right)$ & 14.2 & 104 \\
\hline BSYN 2-2 & $\left(\mu \mathrm{g} \mathrm{g}^{-1}\right)$ & 14.7 & 116 \\
\hline
\end{tabular}

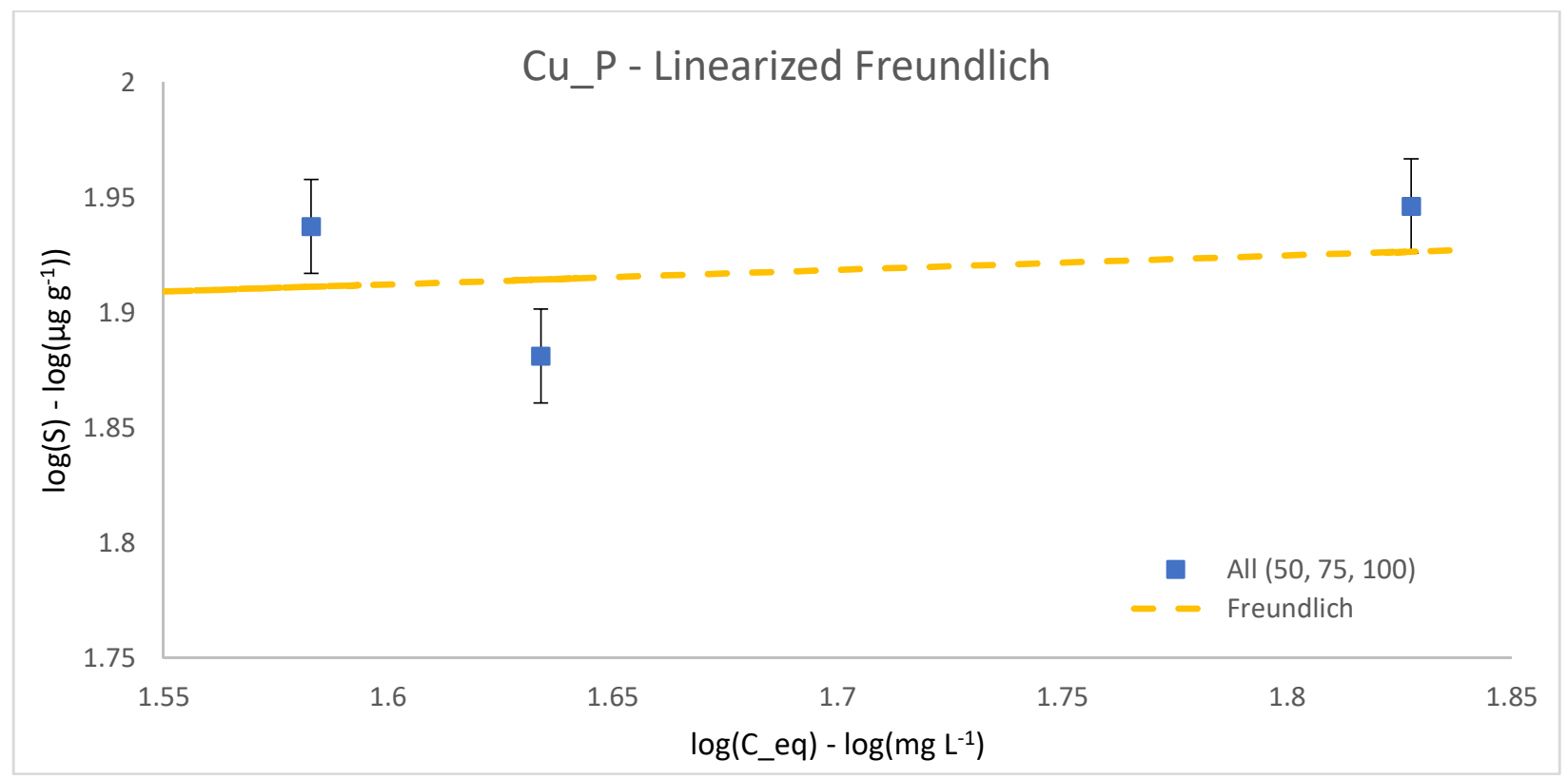

Figure 13. Linearized Freundlich isotherm for single metal Cu-Perlite batch. 


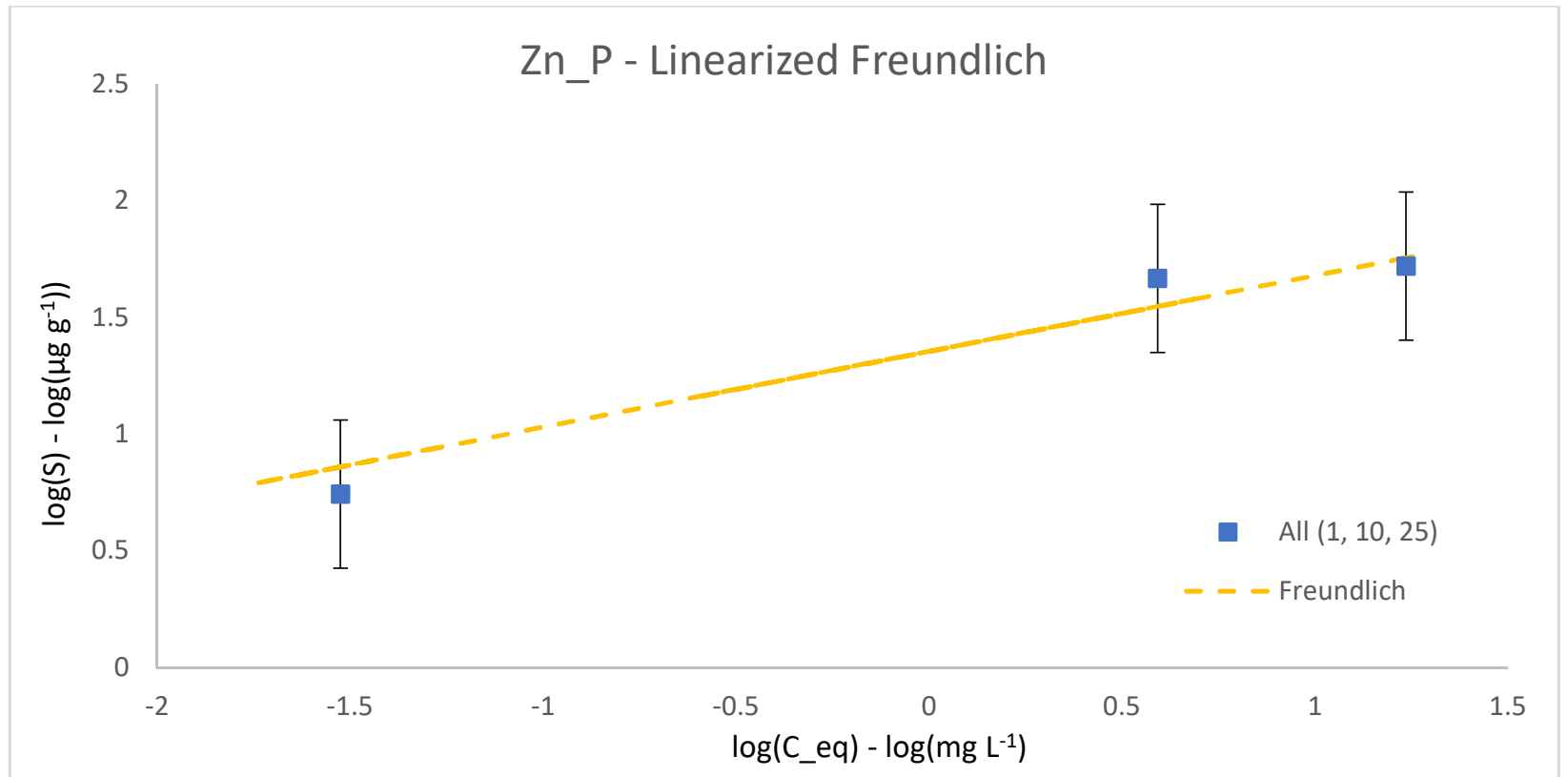

Figure 14. Linearized Freundlich isotherm for single metal Zn-Perlite batch.

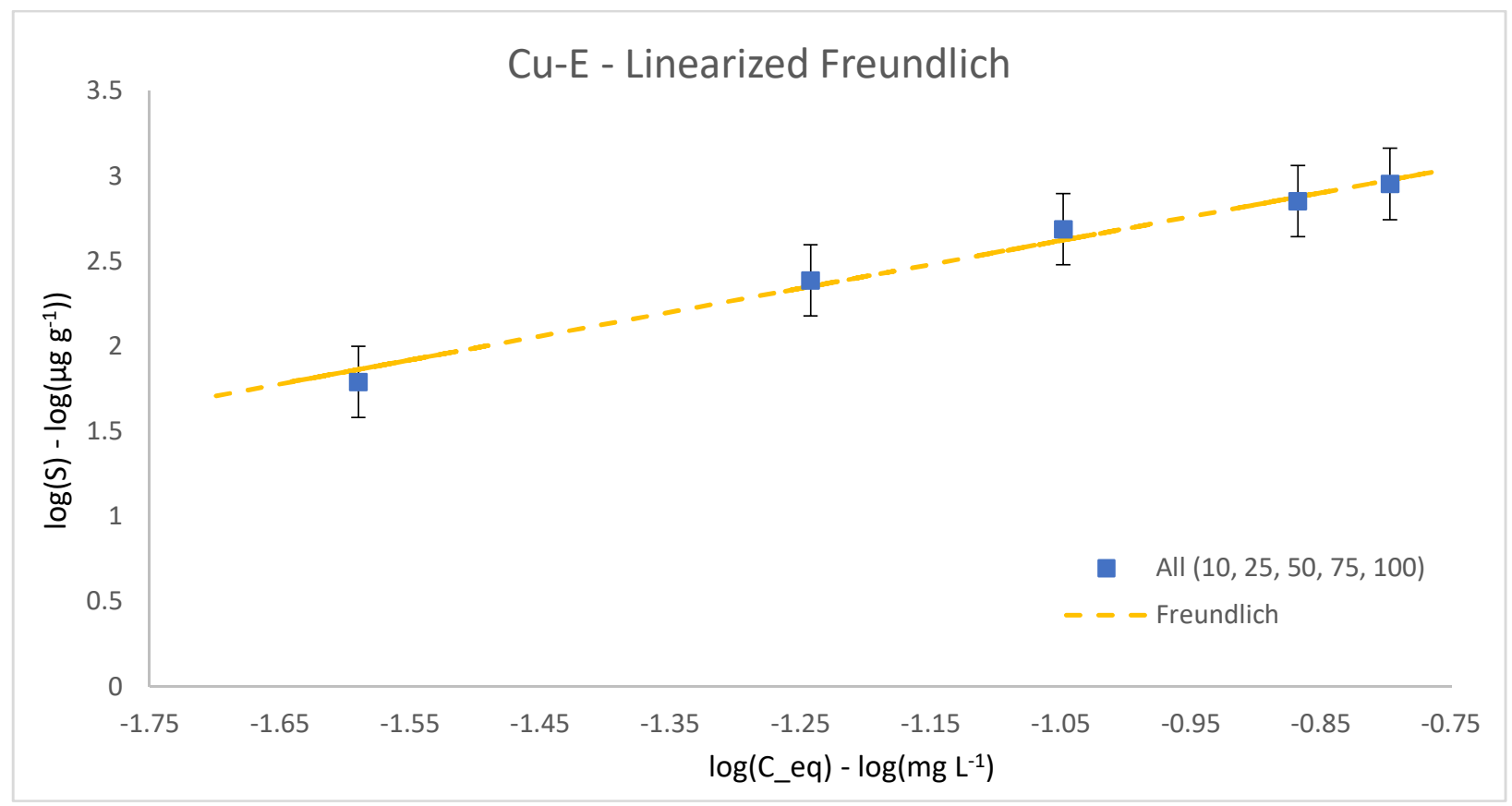

Figure 15. Linearized Freundlich isotherm for single metal Cu-Earthlite ${ }^{\mathrm{TM}}$ batch. 


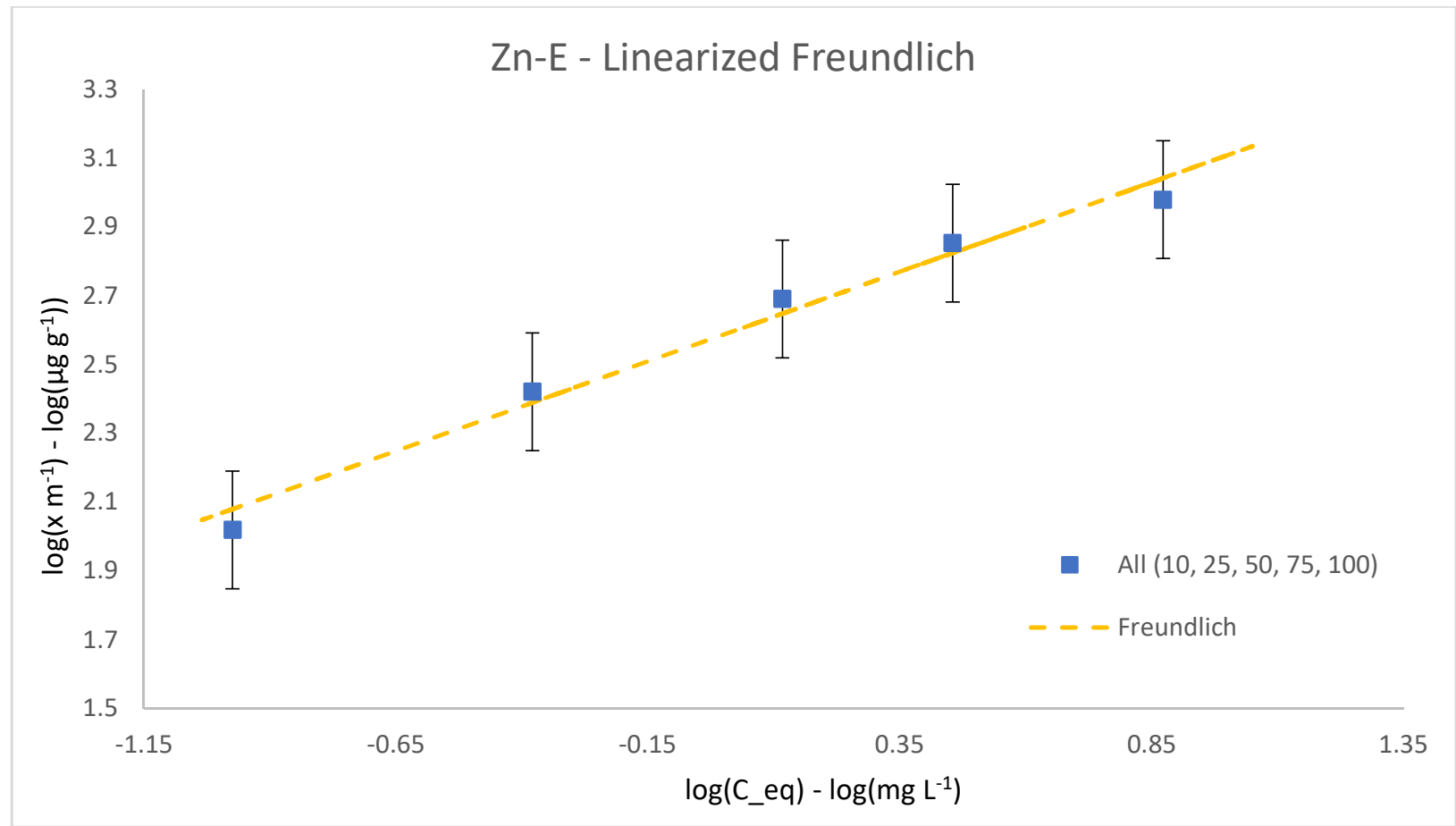

Figure 16. Linearized Freundlich isotherm for single metal Zn-Earthlite ${ }^{\mathrm{TM}}$ batch.

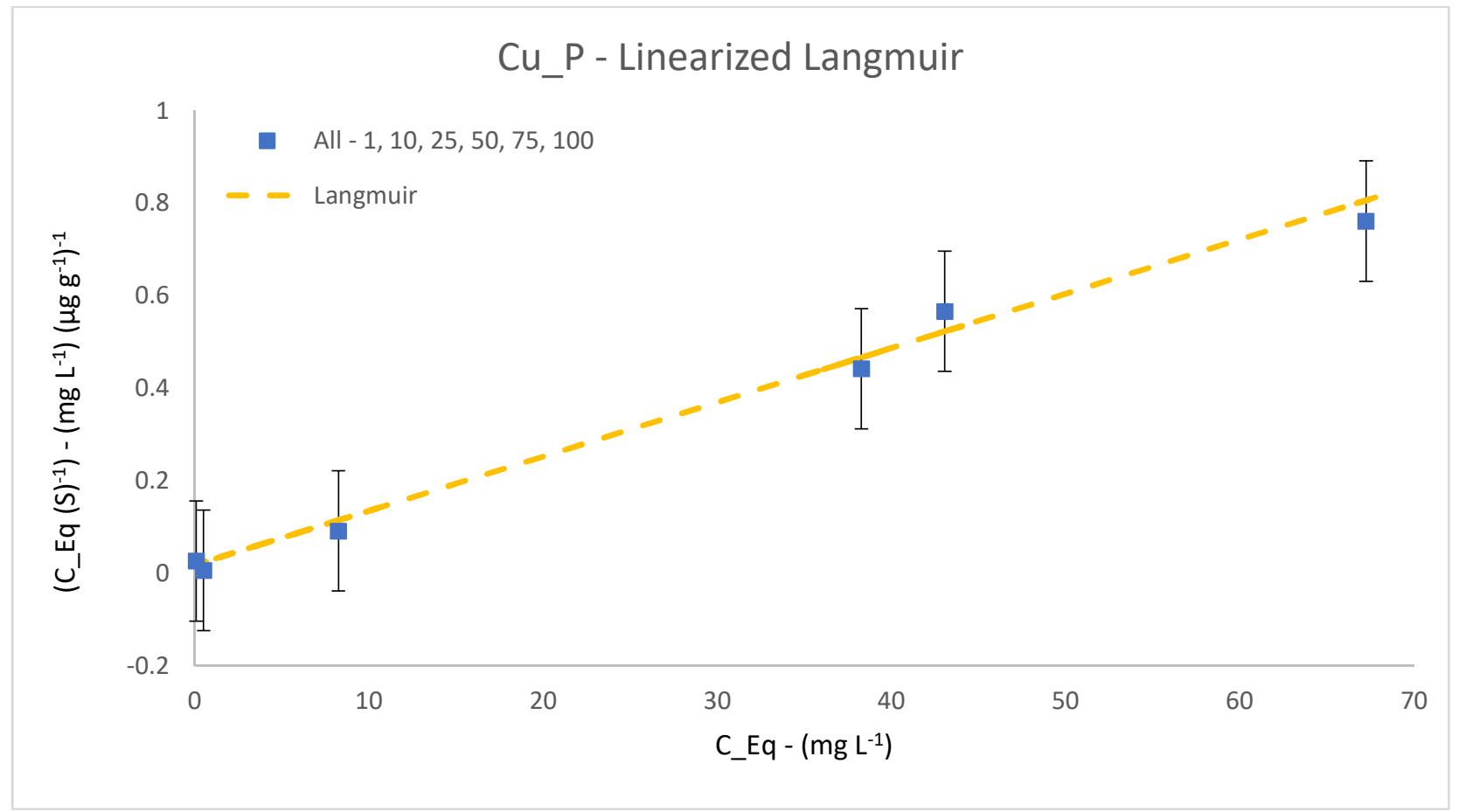

Figure 17. Linearized Langmuir isotherm for single metal Cu-Perlite batch. 


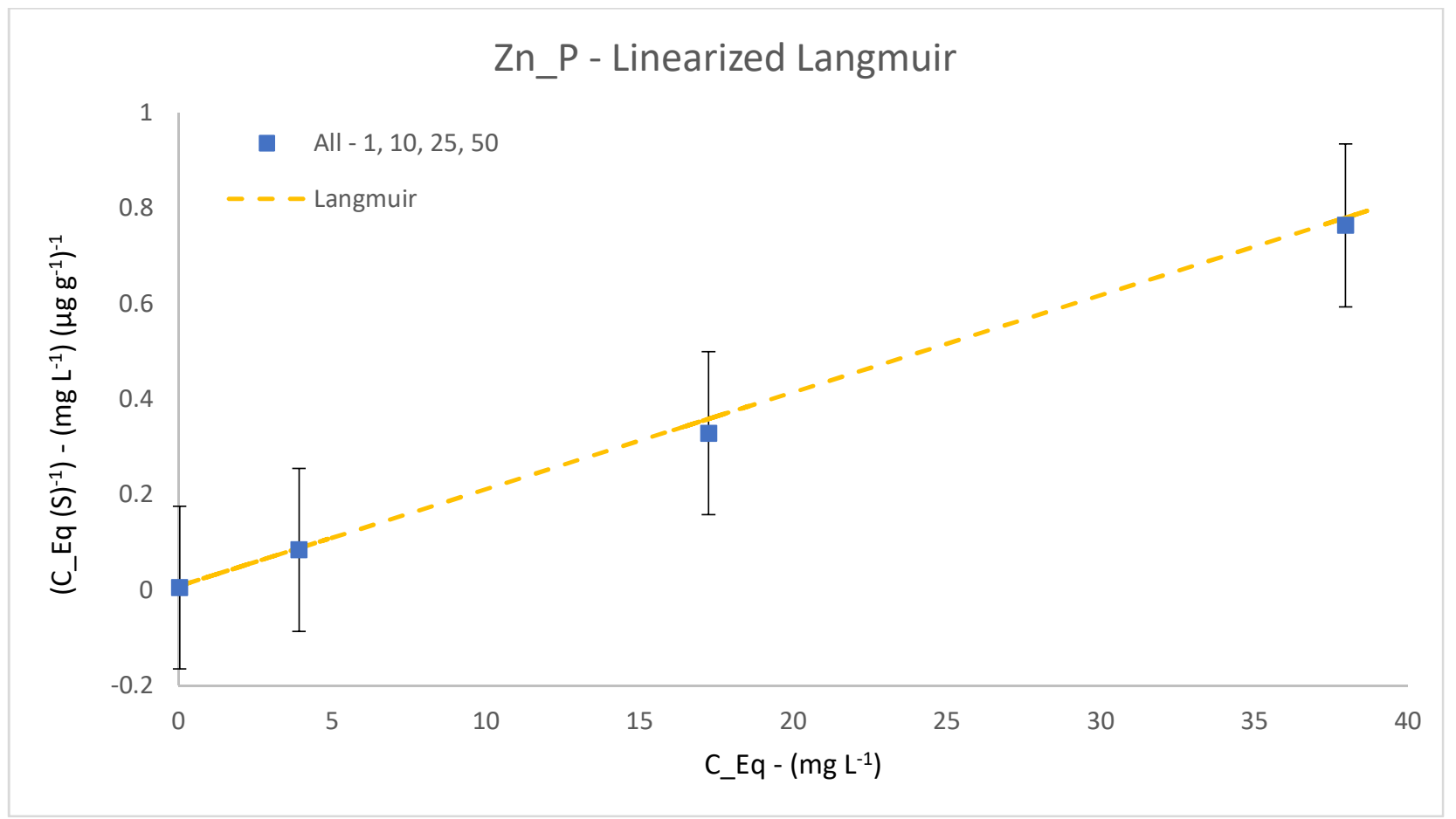

Figure 18. Linearized Langmuir isotherm for single metal Zn-Perlite batch.

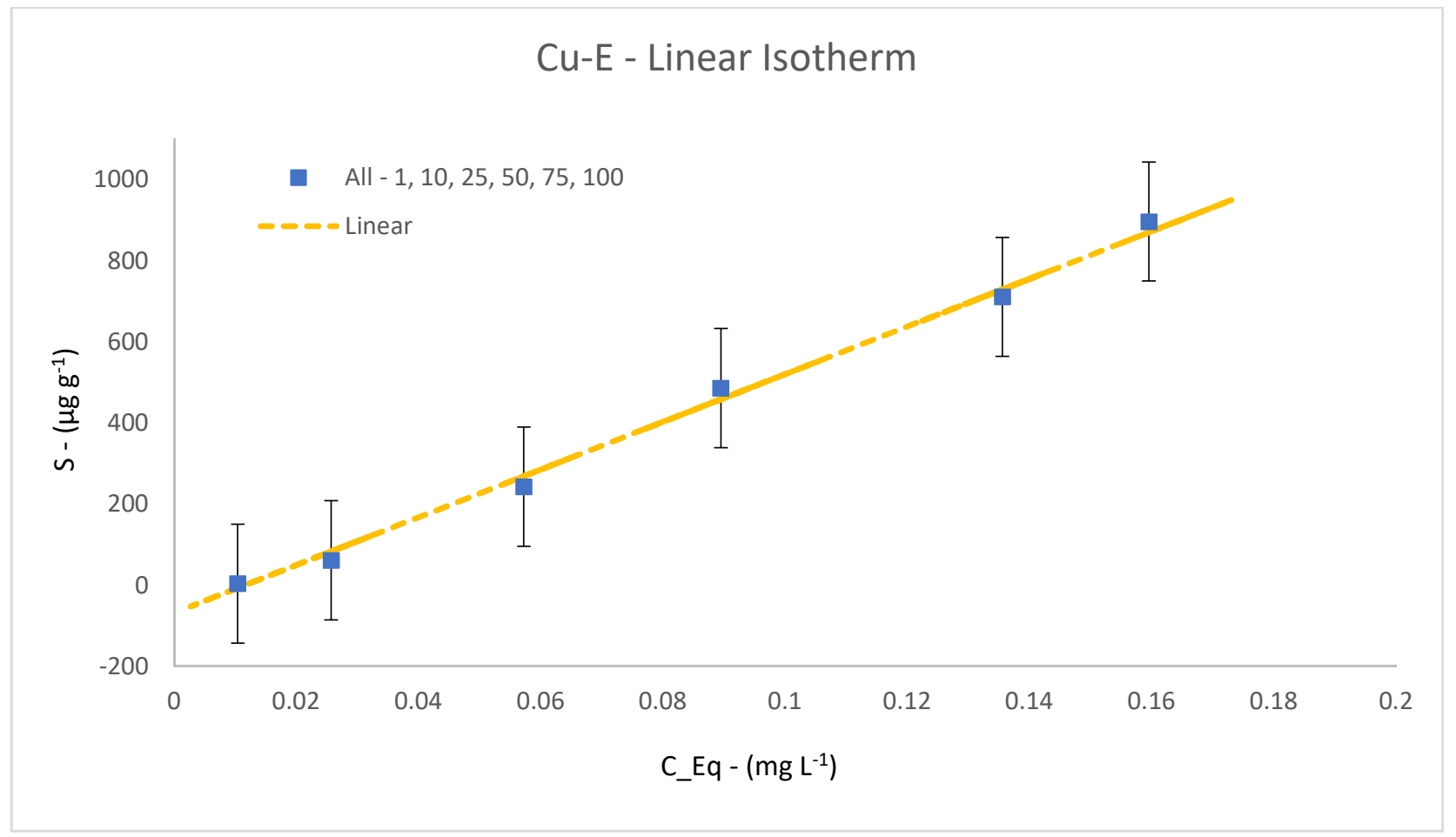

Figure 19. Linear isotherm for single metal Cu-Earthlite ${ }^{\mathrm{TM}}$ batch. 


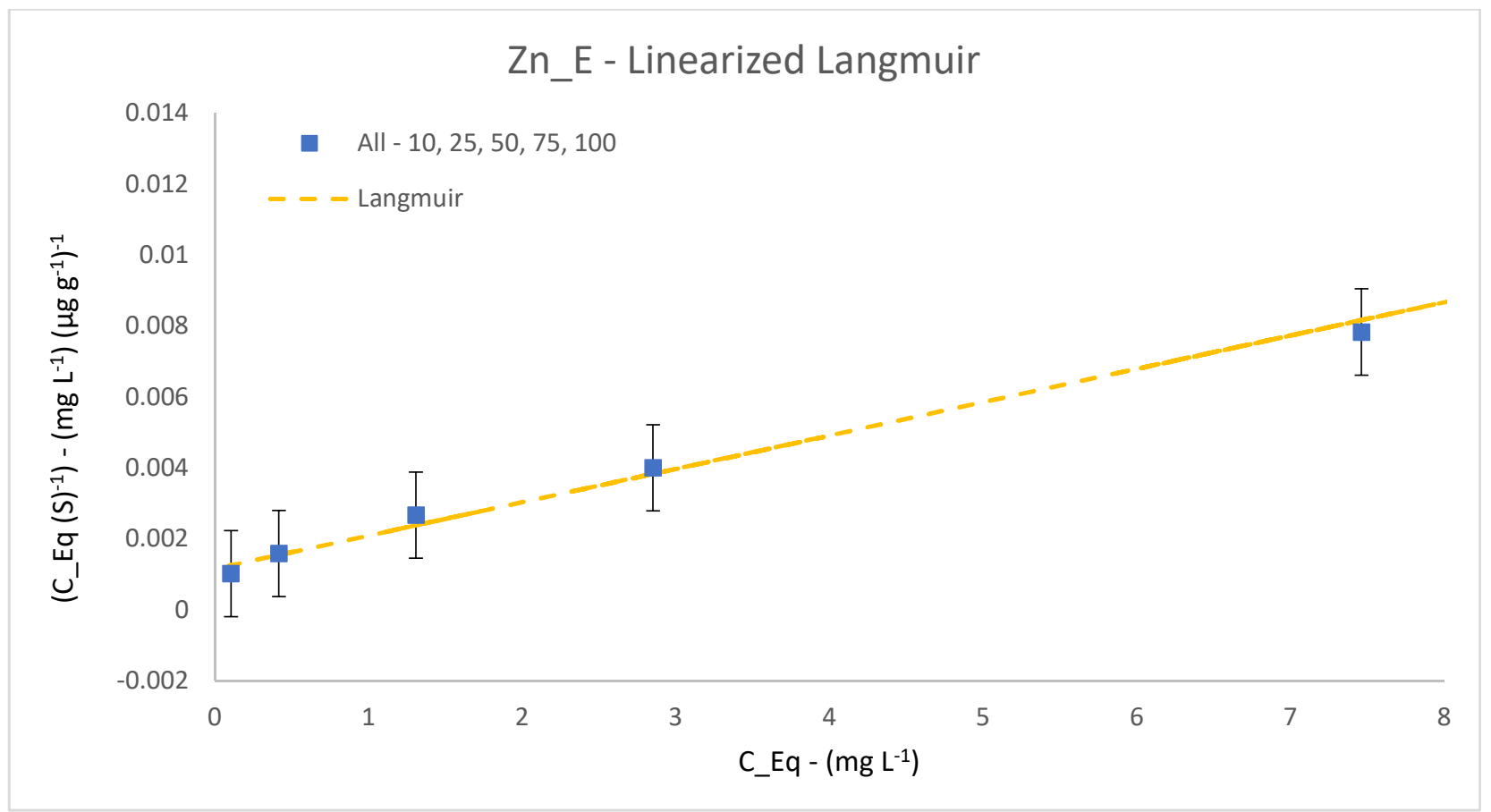

Figure 20. Linearized Langmuir isotherm for single metal Zn- Earthlite ${ }^{\mathrm{TM}}$ batch. 

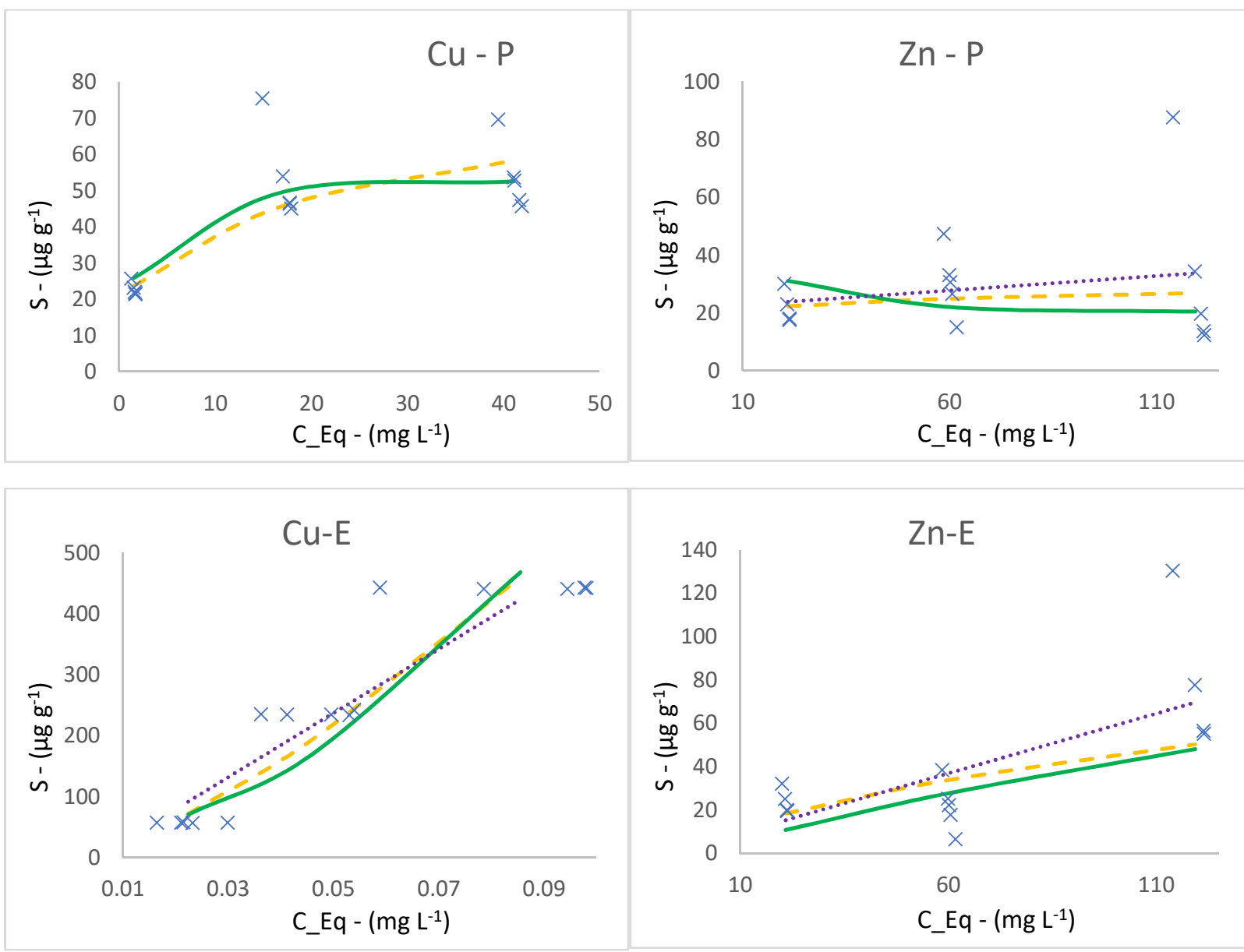

$\times$ Experimental Data $\quad$ - - - Freundlich _ Langmuir $\quad$ _......... Linear

Figures 21 - 24. Competitive batch data for $\mathrm{Cu}$ and $\mathrm{Zn}$ in perlite and Earthlite ${ }^{\mathrm{TM}}$ with best fit Freundlich, Langmuir and/or Linear isotherm models. 